Research papers

\title{
A numerical model analysis of the tidal flows in the Bay of Algeciras, Strait of Gibraltar
}

\author{
S. Sammartino a,*, J. García Lafuente ${ }^{\text {a }}$, J.C. Sánchez Garrido a , F.J. De los Santos ${ }^{\text {b }}$, E. Álvarez

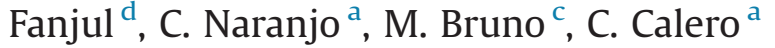 \\ a Physical Oceanography Group, University of Málaga Campus de Teatinos s/n, 29071 Málaga, Spain \\ ${ }^{\mathrm{b}}$ Autoridad Portuaria Bahía de Algeciras, Algeciras, Spain \\ c University of Cádiz, Cádiz, Spain \\ d Puertos del Estado, Madrid, Spain
}

\section{A R T I C L E I N F O}

\section{Article history:}

Received 22 November 2012

Received in revised form

10 October 2013

Accepted 6 November 2013

Available online 15 November 2013

\section{Keywords:}

Bay of Algeciras

Baroclinic tide

Tidal transport

MITgcm

\begin{abstract}
A B S T R A C T
A numerical model has been applied to study the tidal flows of the Bay of Algeciras in the eastern part of the Strait of Gibraltar, focusing on the $M_{2}$ semidiurnal constituent. The numerical model was satisfactorily validated against a comprehensive set of observations collected in the bay in the year 2011 and the model outputs were used for a detailed analysis of the local tidal circulation. The $M_{2}$ net (vertically integrated) transport across the mouth of the bay has an amplitude of $2.7 \times 10^{-3} \mathrm{~Sv}$, while that of the sea surface signal is of $\sim 30 \mathrm{~cm}$ and is in quadrature with this flow. However, the vertically integrated flow is the result of a pronounced baroclinic structure consisting of an upper $(S<37.5)$ and lower $(S>37.5)$ layers, whose associated transports are one order of magnitude higher. This reveals a noticeable internal tide that is characterized by an inward (to the head of the bay) propagation and a likely quarter-wave resonance. During the rising tide, Atlantic water from the strait comes in and produces the thickening of the upper (Atlantic) layer in the bay, while Mediterranean water of the lower layer is pushed out to join the Mediterranean water stream that is flowing to the west along the Strait of Gibraltar. During the falling tide, Atlantic water flows out of the bay and incorporates to the eastward flow in the strait. In this tidal phase, Mediterranean water flows into the bay. Therefore, Atlantic and Mediterranean waters accumulate in the bay during the rising and falling tide, respectively. This pattern is opposite to that observed in the strait, where the Mediterranean layer thickens during the rising tide and becomes thinner during the falling tide. This suggests that the internal tide in the bay is basically determined by the baroclinic forcing at its mouth imposed by the baroclinic tide of the Strait of Gibraltar.
\end{abstract} (c) 2013 Elsevier Ltd. All rights reserved.

\section{Introduction}

The Bay of Algeciras (southwest of Spain) is located at the eastern part of the Strait of Gibraltar (Fig. 1) where the well-known two-way exchange between the Atlantic Ocean and the Mediterranean Sea occurs. The Algeciras port, at the head of the bay, is the second most important port of Spain, with strategic importance in terms of maritime traffic of fuel and general supplies, making the whole area a high risk environment for pollution derived from its commercial activities (http://www.portofalgeciras.com/hand book_2013/).

The bay faces south-southeastward, is $8-10 \mathrm{~km}$ wide and 10-12 km long, with a surface area of about $A_{B}=73 \mathrm{~km}^{2}$, whose end-points are Point Carnero to the west and Point Europa to the

\footnotetext{
* Corresponding author: Tel.: +349521328 49.

E-mail address: ssammartino@ctima.uma.es (S. Sammartino).
}

east (Fig. 1). The bathymetry is characterized by a central canyon that reaches its maximum depth (about $450 \mathrm{~m}$ ) and width at the mouth of the bay. The canyon shifts to the east, leaving a wider continental shelf over the western part of the bay than on the eastern part. The length and width of the bay is comparable to the width of the strait ( $14 \mathrm{~km}$ at its narrowest section) and its influence on the exchange of water through the strait, although very small at a regional scale, could be of concern in its easternmost part.

The nearby Strait of Gibraltar is a well-studied area for its singular hydrodynamics. A few numerical studies of the area have been carried out in the past few decades (Wang, 1989, 1993; Izquierdo et al., 2001; Sannino et al., 2002, 2004; Sánchez-Garrido et al., 2011) in addition to an impressive number of theoretical and experimental studies (see Sánchez-Román et al., 2012 and references therein for a recent review). The strait is characterized by a two-layer baroclinic exchange of fresh and warm Atlantic water spreading into the Mediterranean Sea at the surface, and relatively 


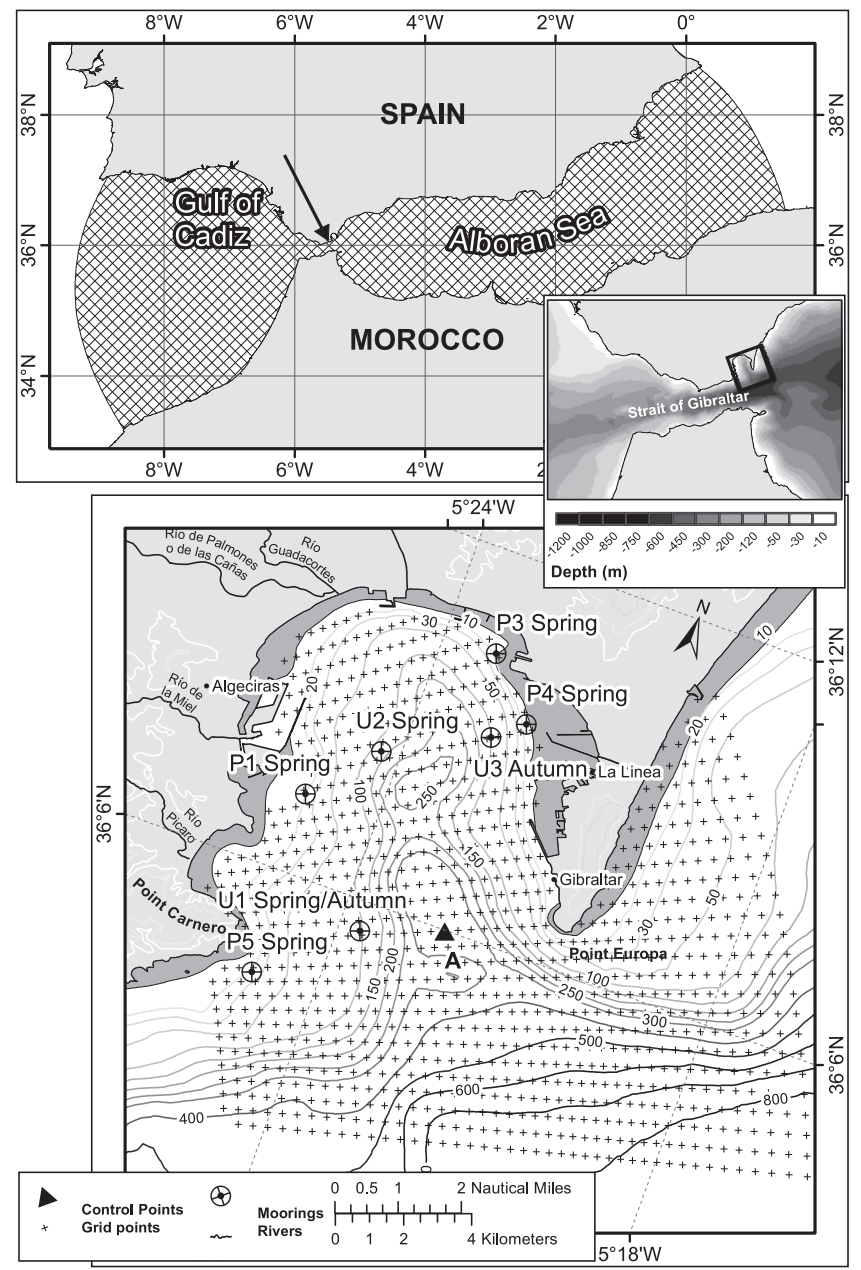

Fig. 1. Map of the study area showing the location of the moorings used in the validation process and the grid points of the model (crossed circles and crosses, respectively). The spatial domain of the model is displayed in the upper pane (crosshatch area). Black triangle (label A) at $36^{\circ} 6.34^{\prime} \mathrm{N}$ and $5^{\circ} 22.37^{\prime} \mathrm{W}$ shows the site where time series discussed in the text have been extracted.

colder and saltier Mediterranean water outflowing to the Atlantic Ocean in the lower layer, each flow being of the order of $0.8 \mathrm{~Sv}$ $\left(1 \mathrm{~Sv}=1 \times 10^{6} \mathrm{~m}^{3} \mathrm{~s}^{-1}\right)$. On shorter time-scales, however, the strait circulation is dominated by tides, whose associated transports have amplitudes three to five times greater (depending on the fortnightly cycle) than the mean baroclinic exchange (García Lafuente et al., 2000). The along-strait vertically averaged tidal currents lead the sea level oscillation by $90^{\circ}$ (Candela et al., 1990; García-Lafuente et al., 1990), indicating a standing wave nature of the external (or barotropic) tide, a fact already pointed out by Defant (1960) in his discussion on the Mediterranean Sea tides. These authors show that the vertically averaged (barotropic) tidal current heads to the Atlantic from low to high water (the raising phase of the tidal cycle, which we shall refer as flood tide) and to the Mediterranean during the falling phase (ebb tide), which is the required flow to match the Atlantic tide in the Gulf of Cadiz, the Atlantic side of the strait (Fig. 1). Further interaction of this barotropic tide with the sharp bathymetry of the strait gives rise to one of the most intense baroclinic tides in the world ocean (Armi and Farmer, 1988; Sánchez-Garrido et al., 2011), which is of concern for the present study.

Differently from the strait, the information in the area of the Bay of Algeciras is rather scarce: existing experimental studies, dealing with the characterization of the strait circulation, include stations inside or near the bay (García-Lafuente et al., 1990;
Candela et al., 1990), while very few studies based on numerical simulations have been published specifically on this area (Álvarez et al., 2011; Periáñez, 2012). Álvarez et al. (2011) describe the propagation of short-period internal waves (period $\sim 20-40 \mathrm{~min}$, near the buoyancy frequency) inside the bay, estimated as highfrequency oscillations of the free-surface elevation. They also indicate an $M_{2}$-driven tidal elevation characterized by a nearly constant amplitude (around $33 \mathrm{~cm}$ ) and a northward propagation, together with a diffraction pattern around the rock of Gibraltar.

A more complete description of the circulation in the bay at tidal time-scales, particularly the semidiurnal scale, and its threedimensional circulation is still lacking. This work presents the results of a three-dimensional model of the Strait of Gibraltar, with enhanced spatial resolution in the Bay of Algeciras. It focuses on the $M_{2}$ constituent, which is the most important one, although some issues related to the fortnightly modulation are also discussed. The model is described in Section 2 and its validation is addressed in Section 3, where two field experiments, accomplished to collect data for this task, are detailed. The numerical outputs are used to describe the $M_{2}$ (representative of the other semidiurnal, less important constituents) tidal circulation in the bay (Section 4). Finally, Section 5 presents the main conclusions of the study.

\section{The model}

The numerical model used in this study is the Massachusetts Institute of Technology general circulation model $(\mathrm{MITg} \mathrm{cm})$ that solves the Boussinesq form of the Reynolds-averaged NavierStokes equations for an incompressible fluid (Marshall et al., 1997). The model domain covers the Gulf of Cadiz and the Alboran Sea (see upper inset in Fig. 1) and is described in detail next.

The model setup is similar to that used by Sánchez-Garrido et al. (2011), who conducted a number of numerical experiments to study the generation process of nonlinear internal waves over the main sill of the Strait of Gibraltar. The main difference concerns the horizontal model resolution that here is somewhat coarser with mesh sizes of 350-550 $\mathrm{m}$ in the bay and the Strait of Gibraltar, and less than $3 \mathrm{~km}$ over the rest of domain. The grid is unevenly spaced in the vertical, with thinner cells in the upper layers, and a total of 46 cells ( 23 cells in the bay area, up to $450 \mathrm{~m}$ depth at the mouth). Another difference concerns the hydrostatic approximation, which is adopted here. This is justified by (1) our interest in the long tidal $M_{2}$ internal wave that is fundamentally hydrostatic and (2) the fact that at this resolution the nonhydrostatic code has a minor impact on the strait flows (Sannino et al., 2013). Additionally, this approximation reduces significantly the computational cost of the model, which is crucial in an operational system in which the model is currently integrated (http://sampa-apba.puertos.es).

The bottom topography derives from the merging of the GEBCO 1-min resolution gridded bathymetry (GEBCO, 2003) and the highresolution bathymetric chart of the Strait of Gibraltar by Sanz et al. (1991) and is implemented in the model by partial vertical cells.

Vertical eddy viscosity $v$ and diffusivity $k$ are Richardsonnumber dependent (Pacanowski and Philander, 1981):

$v=\frac{v_{0}}{(1+\alpha R i)^{n}}+v_{b}, \quad k=\frac{v}{(1+\alpha R i)}+k_{b}$

where $R i=N^{2}(z) /\left(u_{z}^{2}+v_{z}^{2}\right)$ is the Richardson number, $v_{b}=1.5 \times$ $10^{-4} \mathrm{~m}^{2} \mathrm{~s}^{-1}, k_{b}=1 \times 10^{-7} \mathrm{~m}^{2} \mathrm{~s}^{-1}$ are the background values, and $v_{0}=1.5 \times 10^{-2} \mathrm{~m}^{2} \mathrm{~s}^{-1}, \alpha=5$ and $n=1$ are adjustable parameters. This scheme was chosen because of its suitability to parameterize turbulent mixing and dissipation in high-resolution models induced by high frequency (period $\sim 15-20 \mathrm{~min}$ ) internal waves 
(Vlasenko et al., 2005), which are very relevant features in the Strait of Gibraltar (Sánchez-Garrido et al., 2008). Horizontal eddy diffusivity is $k_{h}=10^{-1} \mathrm{~m}^{2} \mathrm{~s}^{-1}$, and horizontal viscosity is calculated following the parameterization of Leith (1968).

Different conditions are imposed at the boundaries of the model. Hourly values of surface wind-stress, fresh water and heat surface fluxes, based on the HIRLAM model (Cats and Wolters, 1996) provided by the Spanish Meteorological Agency, force the model at the open, free surface. At the seafloor and solid lateral boundaries, no-slip conditions are prescribed. Friction is further increased at the bottom boundary by imposing a quadratic bottom drag $\tau=C_{d} \rho u^{2}$ acting on the grid cell on top of that implied by the bottom drag (Legg et al., 2006). The numerical value of the drag coefficient $C_{d}$ has been set to $2 \times 10^{-3}$, within the range of estimated values (Thorpe, 2007). Friction at the solid lateral boundaries is not modified by this additional drag.

Conditions at the vertical open boundaries (Mediterranean and Atlantic sides of the model) are more sophisticated since they incorporate three different mechanisms/forces. The first forcing is baroclinic in nature and enters the model by prescribing the daily values of the baroclinic fields of temperature, salinity and horizontal velocity provided by the MyOcean-MED model (Oddo et al., 2009), which is one-way coupled to our model. MyOcean-MED simulates only partially subinertial flows through the Strait of Gibraltar: it can reproduce wind-induced flows and the small net inflow $(\sim 0.05 \mathrm{~Sv})$ caused by the net evaporative losses in the Mediterranean basin, but not subinertial flows related to changes in atmospheric pressure, since it is not included in the model. It is known, however, that flows induced by the variation of atmospheric pressure over the Mediterranean basin are typically one order of magnitude greater than the net inflow caused by evaporation (Candela et al., 1989; García-Lafuente et al., 2002) and they have to be included in our model. To prevent a double imposition of wind-induced flows, which would add to the windstress forcing already acting at the free surface, the velocity component normal to the open boundaries provided by MyOcean-MED is corrected by adding a small $\left(O\left(10^{-4} \mathrm{~m} \mathrm{~s}^{-1}\right)\right)$ barotropic velocity. Thus, MyOcean-MED velocities preserve the volume in the domain and cause the net volume transport across the boundaries to be null.

The second forcing is the above commented remote atmospheric-pressure effect on the exchange through Gibraltar, which is barotropic in nature. It is suitably reproduced by the HAMSOM model (García-Lafuente et al., 2002), which is successfully integrated in the Nivmar storm surge forecast system (Álvarez-Fanjul et al., 2001). The barotropic velocities prescribed by HAMSOM at the open boundaries are added to the baroclinic field of MyOceanMED to incorporate this remote forcing into our model. Finally, a third forcing is introduced by generating barotropic tidal currents at the open boundaries using the harmonic constants derived by the Mog2D model (Carrere and Lyard, 2003).

Therefore, the final velocity $\vec{u}$ prescribed at the vertical eastern (Mediterranean side) and western (Atlantic side) open boundaries may be summarized as

$\vec{u}(y, z, t)=\vec{u}_{M}(y, z, t)+\vec{u}_{H}(y, t)+\vec{u}_{T}(y, t)$

where $\vec{u}_{M}, \vec{u}_{H}, \vec{u}_{T}$ are the velocity fields provided by My-OceanMED, HAMSOM and Mog2D models, the first one verifying $\int_{o b} \vec{u}_{M}(y, z, t) d y d z=0$ (the integral extending over both open boundaries).

The behavior of the model at the free surface is defined on the basis of the Homogeneous Neumann boundary condition $(\partial \eta / \partial \mathbf{n}=0)$, while the wave reflections at the open boundaries are minimized by adding a Newtonian relaxation term to the tracer equations over the boundary area and implementing the flow relaxation scheme proposed by Carter and Merrield (2007) for the velocity field. Additionally, the open boundaries are set sufficiently far (see Fig. 1) to prevent the intrusion of possible spurious signals in the zone of interest of this study (the bay and the strait).

The model outputs analyzed in this paper refer to two periods of hindcast in year 2011: the spring (from mid-March to mid-June) and autumn (from mid-September to the end of November) periods, when observations were collected for the model validation. The outputs of the model are hourly values of 3D velocity, salinity and temperature fields, as well as sea surface height ( $\mathrm{SSH}$ hereinafter).

\section{Model validation}

Two field campaigns were carried out to validate the model. The observations were collected at the stations indicated in Table 1 (see also Fig. 1). Four shallow stations, with depths lower than $35 \mathrm{~m}$ (prefix $P$ ), and three others deeper, at around $100 \mathrm{~m}$ (prefix $U$ ), were deployed during the two mentioned periods. The four shallow and two of the deeper stations were installed in spring (suffix $s$ ), while U1 and U3 stations were deployed in autumn (suffix $a$ ).

The shallower stations were equipped with a single Acoustic Doppler Current Profiler (ADP), model AWAC by NORTEK. They were placed pointing upward on the seafloor inside a standing tripod. Depending on the bottom depth and the ADP configuration, the number of cells resolved by the profiler varied from 13 to 25 . The deeper stations consisted of an ADP pointing upward (model CONTINENTAL by NORTEK) embedded in a sub-surface head buoy at 90-100 $\mathrm{m}$ depth, and a conductivity/temperature sensor (CT model SBE37 by SeaBird) placed $3 \mathrm{~m}$ below. Conductivity data have been converted in salinity, expressed in $\mathrm{g} / \mathrm{kg}$. An acoustic release linked to an anchor completed the line. The ADPs were equipped with pressure and temperature sensors. Because of the low precision and the thermal inertia of the latter, temperature records from the ADP were discarded when temperature from a CT sensor was available at the same station (see Table 1 for more details).

Observations at a given point have been compared with the model outputs at the nearest grid point. The distance between both points was always less than $150 \mathrm{~m}$ and typically less than $100 \mathrm{~m}$. In the inner areas of the bay, the near shore stations are sensitive to two factors that contribute to diminish the performance of the model. Firstly, the imposed no-slip condition that affects the model ability to reproduce the velocity field in the boundary grid points (Sánchez-Garrido et al., 2011) and, secondly, the presence of man-made structures of sub-grid scale (docks, barriers, etc.) that are not resolved by the model. This is a critical issue in some stations as, for instance, P1s (see Fig. 1). The combination of both factors is a source of discrepancy between the observations and the model outputs.

Validation has focused on the tidal time-scale since the study deals with the semidiurnal $M_{2}$ constituent. The analysis tool employed has been the classical tidal harmonic package (Pawlowicz et al., 2002). The validation includes the analysis of the external (or barotropic) and baroclinic tides.

\subsection{The barotropic tide}

The observed SSH was recovered from the pressure sensor of the instruments using the hydrostatic approximation. The numerical model outputs SSH directly and no conversion is required. Table 2 presents the harmonic constants of SSH for $M_{2}$ and $S_{2}$ constituents. For $M_{2}$, the observations give SSH amplitudes about 2 and $4 \mathrm{~cm}$ higher than the model in the deep and shallow stations, respectively. Considering the confidence intervals, the maximum (relative) difference between both sets of parameters varies from $5 \%$ to $11 \%$ in the shallow and is less than $5 \%$ in the deep stations. The phases compare even better, returning a complete 
Table 1

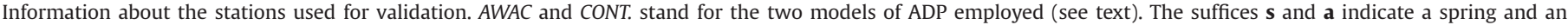
autumn station, respectively.

\begin{tabular}{|c|c|c|c|c|c|c|c|c|}
\hline \multirow[t]{2}{*}{ Station } & \multirow[t]{2}{*}{ Instrum. } & \multicolumn{2}{|l|}{ Position } & \multirow[t]{2}{*}{ Depth } & \multicolumn{2}{|l|}{ Period } & \multirow[t]{2}{*}{ Sampl. int. (min) } & \multirow[t]{2}{*}{ \# cells } \\
\hline & & Latitude & Longitude & & From & To & & \\
\hline P1s & ADP-AWAC & $36^{\circ} 07.28^{\prime} \mathrm{N}$ & $5^{\circ} 25.21^{\prime} \mathrm{W}$ & 35 & 04.29 .11 & 06.22 .11 & 20 & 15 \\
\hline P3s & ADP-AWAC & $36^{\circ} 10.40^{\prime} \mathrm{N}$ & $5^{\circ} 23.13^{\prime} \mathrm{W}$ & 26 & 04.29 .11 & 06.23 .11 & 20 & 13 \\
\hline P4s & ADP-AWAC & $36^{\circ} 09.51^{\prime} \mathrm{N}$ & $5^{\circ} 22.30^{\prime} \mathrm{W}$ & 25 & 04.29 .11 & 06.22 .11 & 20 & 13 \\
\hline P5s & ADP-AWAC & $36^{\circ} 04.33^{\prime} \mathrm{N}$ & $5^{\circ} 25.05^{\prime} \mathrm{W}$ & 29 & 04.29 .11 & 06.23 .11 & 20 & 25 \\
\hline U1s & ADP-CONT. + CT & $36^{\circ} 05.53^{\prime} \mathrm{N}$ & $5^{\circ} 23.66^{\prime} \mathrm{W}$ & $94(\mathrm{ADP}) / 97(\mathrm{CT})$ & 03.29 .11 & 06.07 .11 & $30(\mathrm{ADP}) / 1(\mathrm{CT})$ & 16 (ADP) \\
\hline $\mathrm{U} 2 \mathrm{~s}$ & ADP-CONT. + CT & $36^{\circ} 08.32^{\prime} \mathrm{N}$ & $5^{\circ} 24.31^{\prime} \mathrm{W}$ & $106(\mathrm{ADP}) / 109(\mathrm{CT})$ & 03.29.11 & 06.07 .11 & $30(\mathrm{ADP}) / 1(\mathrm{CT})$ & 19 (ADP) \\
\hline U1a & ADP-CONT. & $36^{\circ} 05.53^{\prime} \mathrm{N}$ & $5^{\circ} 23.66^{\prime} \mathrm{W}$ & 92 & 10.06 .11 & 02.27 .12 & 3 & 16 \\
\hline U3a & ADP-CONT. + CT & $36^{\circ} 09.14^{\prime} \mathrm{N}$ & $5^{\circ} 22.75^{\prime} \mathrm{W}$ & $94(\mathrm{ADP}) / 97(\mathrm{CT})$ & 10.06 .11 & 11.15 .11 & $3(\mathrm{ADP}) / 2(\mathrm{CT})$ & 16 (ADP) \\
\hline
\end{tabular}

Table 2

Results of the harmonic analysis performed on measured and modeled SSH data. Phases are referred to Greenwich meridian. The percentage of explained variance (not shown) ranges from $90.8 \%$ in station U1s to $98.2 \%$ in station U2s, with a mean value of $95.9 \%$ for the whole set of stations.

\begin{tabular}{|c|c|c|c|c|c|}
\hline \multicolumn{2}{|c|}{ Station } & \multicolumn{2}{|l|}{ Measured } & \multicolumn{2}{|l|}{ Modeled } \\
\hline & & Amplitude (cm) & Phase $\left(^{\circ}\right)$ & Amplitude (cm) & Phase $\left({ }^{\circ}\right)$ \\
\hline \multirow[t]{2}{*}{ P1s } & $M_{2}$ & $32.6 \pm 0.5$ & $49.0 \pm 1.0$ & $28.2 \pm 0.4$ & $50.0 \pm 1.0$ \\
\hline & $S_{2}$ & $11.0 \pm 0.5$ & $77.5 \pm 3.0$ & $10.4 \pm 0.4$ & $69.6 \pm 2.0$ \\
\hline \multirow[t]{2}{*}{ P3s } & $M_{2}$ & $33.3 \pm 0.7$ & $49.0 \pm 1.5$ & $29.4 \pm 0.5$ & $50.5 \pm 1.0$ \\
\hline & $S_{2}$ & $11.0 \pm 0.7$ & $79.0 \pm 4.0$ & $10.6 \pm 0.5$ & $72.0 \pm 2.5$ \\
\hline \multirow[t]{2}{*}{$\mathrm{P} 4 \mathrm{~s}$} & $M_{2}$ & $32.4 \pm 1.2$ & $54.5 \pm 2.0$ & $29.1 \pm 0.4$ & $50.0 \pm 1.0$ \\
\hline & $S_{2}$ & $10.7 \pm 1.2$ & $86.0 \pm 8.0$ & $10.7 \pm 0.4$ & $71.0 \pm 2.5$ \\
\hline \multirow[t]{2}{*}{ P5s } & $M_{2}$ & $32.0 \pm 0.5$ & $46.0 \pm 1.0$ & $27.6 \pm 0.4$ & $50.0 \pm 1.0$ \\
\hline & $S_{2}$ & $11.0 \pm 0.5$ & $73.5 \pm 3.0$ & $10.5 \pm 0.4$ & $67.0 \pm 2.0$ \\
\hline \multirow{2}{*}{ U1s } & $M_{2}$ & $29.5 \pm 0.3$ & $47.0 \pm 1.0$ & $27.5 \pm 0.4$ & $50.5 \pm 1.0$ \\
\hline & $S_{2}$ & $10.3 \pm 0.3$ & $72.5 \pm 2.0$ & $10.3 \pm 0.4$ & $68.5 \pm 2.0$ \\
\hline \multirow[t]{2}{*}{$\mathrm{U} 2 \mathrm{~s}$} & $M_{2}$ & $30.4 \pm 0.3$ & $47.5 \pm 1.0$ & $28.6 \pm 0.4$ & $50.5 \pm 1.0$ \\
\hline & $S_{2}$ & $10.7 \pm 0.3$ & $73.0 \pm 2.0$ & $10.5 \pm 0.4$ & $70.5 \pm 2.0$ \\
\hline \multirow[t]{2}{*}{ U1a } & $M_{2}$ & $29.0 \pm 0.4$ & $49.0 \pm 1.0$ & $27.1 \pm 0.6$ & $50.0 \pm 1.0$ \\
\hline & $S_{2}$ & $11.2 \pm 0.4$ & $69.0 \pm 2.5$ & $10.5 \pm 0.6$ & $67.1 \pm 2.0$ \\
\hline \multirow[t]{2}{*}{ U3a } & $M_{2}$ & $30.2 \pm 0.4$ & $49.5 \pm 1.0$ & $28.4 \pm 0.6$ & $48.5 \pm 1.5$ \\
\hline & $S_{2}$ & $11.2 \pm 0.4$ & $67.0 \pm 1.5$ & $11.1 \pm 0.6$ & $69.5 \pm 3.0$ \\
\hline
\end{tabular}

coincidence within the confidence intervals for stations P1s, P3s, U1a and U3a and only $\sim 2^{\circ}$ (or $\sim 4$ min for $M_{2}$ frequency) of discrepancy for P4s, U1s and U2s. Station P5s shows the higher discrepancy of $4.4^{\circ}$. For $S_{2}$, the amplitude of all stations and the phases of the deeper ones coincide within the confidence intervals with the modeled values. For the shallow stations the phase shows a discrepancy of $9^{\circ}$ on average, which reduces to $\sim 5^{\circ}$ if the confidence intervals are taken into account.

Directly related to the SSH oscillation is the vertically averaged velocity, which has been also analyzed and compared in the observations and in the numerical outputs at the same stations as in Table 2. The explained variance is lower than in the case of SSH data (around $45-55 \%$, a similar percentage in both datasets), which is an expected result since other factors of similar or greater importance than tides contribute to modify the actual current, meteorological forcing in particular. Confidence intervals are correspondingly greater and, within these intervals, the harmonic constants of observations and model outputs agree satisfactorily except for two stations (P5s and U1s) where observations show greater amplitude. An interesting result is that the average phase in the deep stations, less influenced by bottom friction and therefore more representative of tidal circulation, is close to $315-320^{\circ}\left(325 \pm 17^{\circ}\right.$ for observations, $308 \pm 12^{\circ}$ for model outputs) or around $90^{\circ}$ out of phase with SSH (Table 2). This pattern reflects standing wave characteristics, which is an expected result from observations taking into account that the bay is part of the Western Mediterranean - Strait of Gibraltar system where the external tide behaves like a standing wave (Defant, 1960; García-Lafuente et al., 1990; Candela et al., 1990) and an encouraging output of the numerical model since it captures this basic feature.

\subsection{Internal tide}

Internal tide is typical of stratified flows and its more obvious manifestation is the oscillation of the internal surfaces that induces periodic fluctuations of fluid properties (temperature and salinity) at fixed depths.

Mean values and harmonic constants of temperature and salinity calculated from measured and modeled data agree satisfactorily (see Table 1 in supplementary material in the online version of the paper). Fig. 2a shows a fragment of the time series of measured and modeled salinity in station U2s, as an example of the satisfactory performance of the model. The $M_{2}$ signal-tonoise ratio (estimated as the ratio between the computed amplitude and its uncertainty) is one order of magnitude greater than that obtained for the other constituents in both modeled and measured data, revealing the prevailing role of $M_{2}$ in the internal tide.

The vertical variation of the horizontal tidal velocity, another characteristic of the internal tides, for a shallow (P4s) and a deep (U1a) station, is shown in Fig. 2. They cover both types of stations and periods of sampling. In the shallow station (Fig. 2b-e) and in both data sets, the structure is rather barotropic, with a decrease of amplitudes toward the bottom, more noticeable in the modeled data. This feature is a consequence of the bottom friction rather than the internal structure associated with the stratification, which is very weak in these shallow stations. In the deep stations (Fig. 2f-i), the baroclinic structure is much more evident. Actually, the change of phase reflects a clear rotation of the horizontal current with depth (a complete $180^{\circ}$ rotation in the modeled data), strongly suggesting the presence of a first-mode baroclinic tide. The agreement between observations and modeled data is very satisfactory, taking into account the intermittency and non-deterministic nature of the internal tide. The agreement is better in the deep station, a fact clearly shown in the time series presented in Fig. $2 \mathrm{j}$.

Even when the model validation is quite satisfactory, which makes the model suitable for being integrated in operational oceanography models (as it is actually the case), some small discrepancies with observations still need to be worked out. However, the agreement between observations and model is satisfactory enough to justify its use as a diagnostic tool that helps understanding processes. Within this frame the model outputs are interpreted in the next sections of this study. 
a

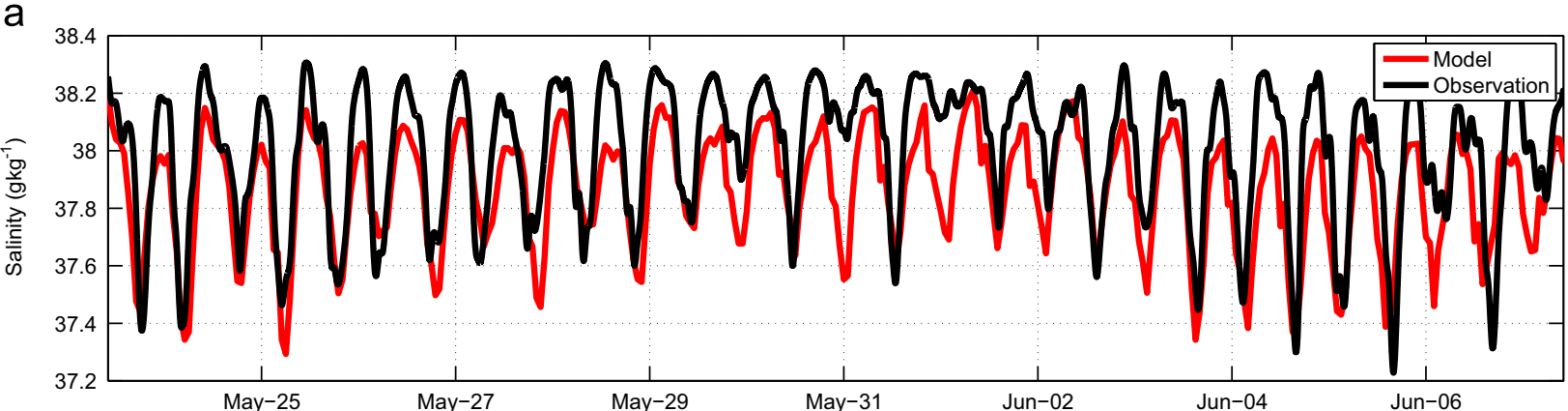

b

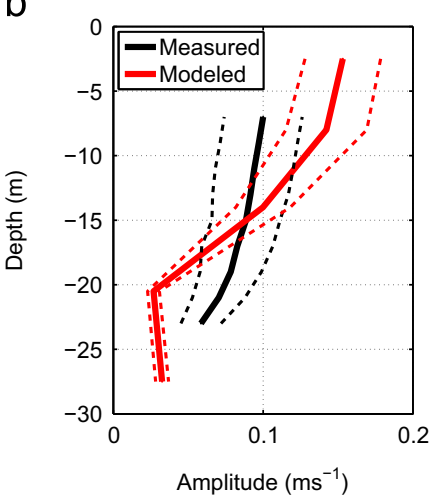

f

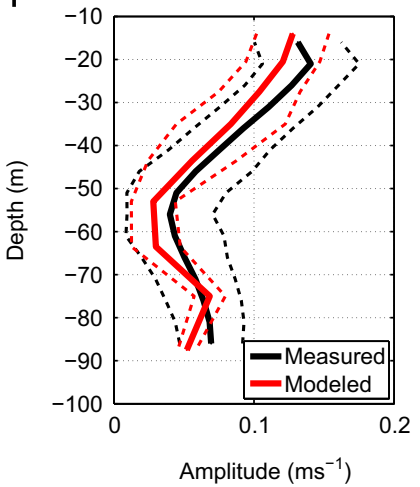

C

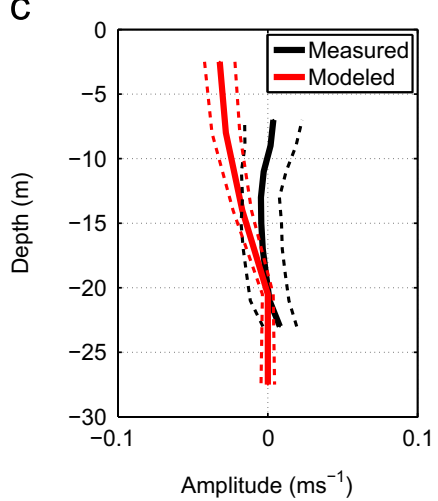

9

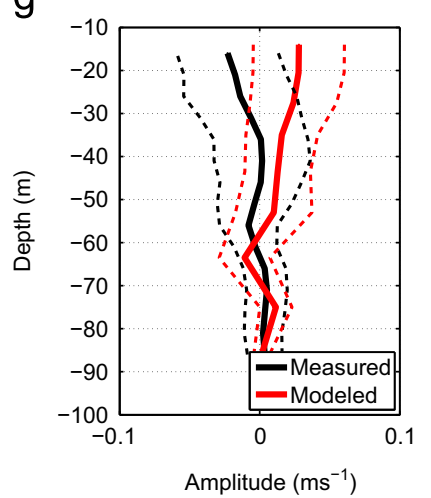

d

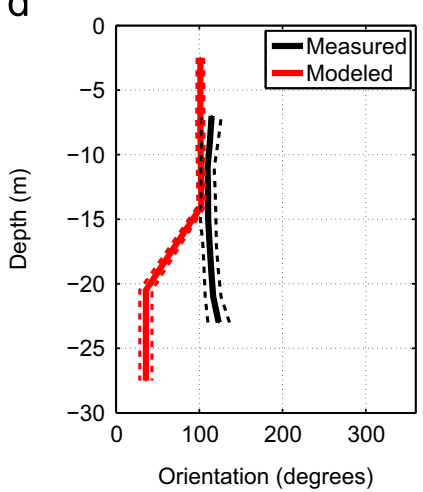

$\mathrm{h}$

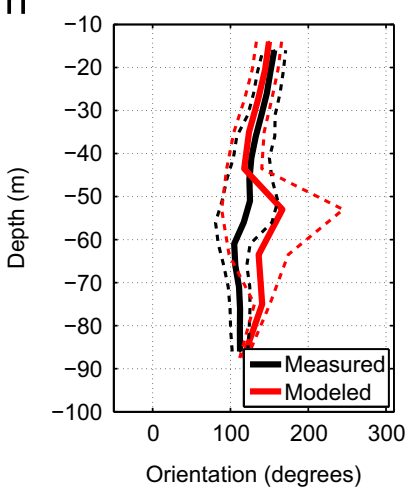

e

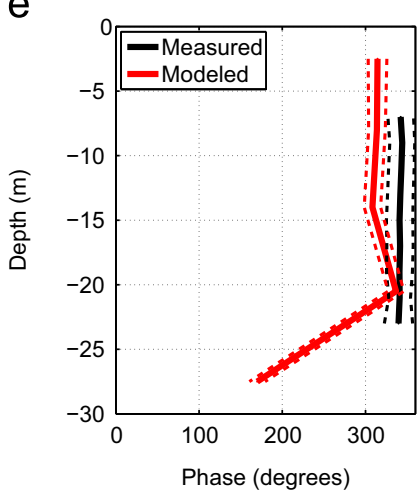

i

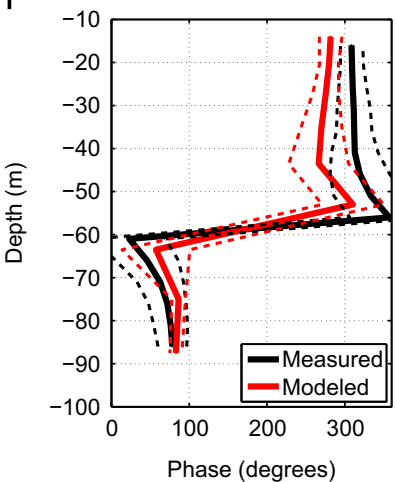

j

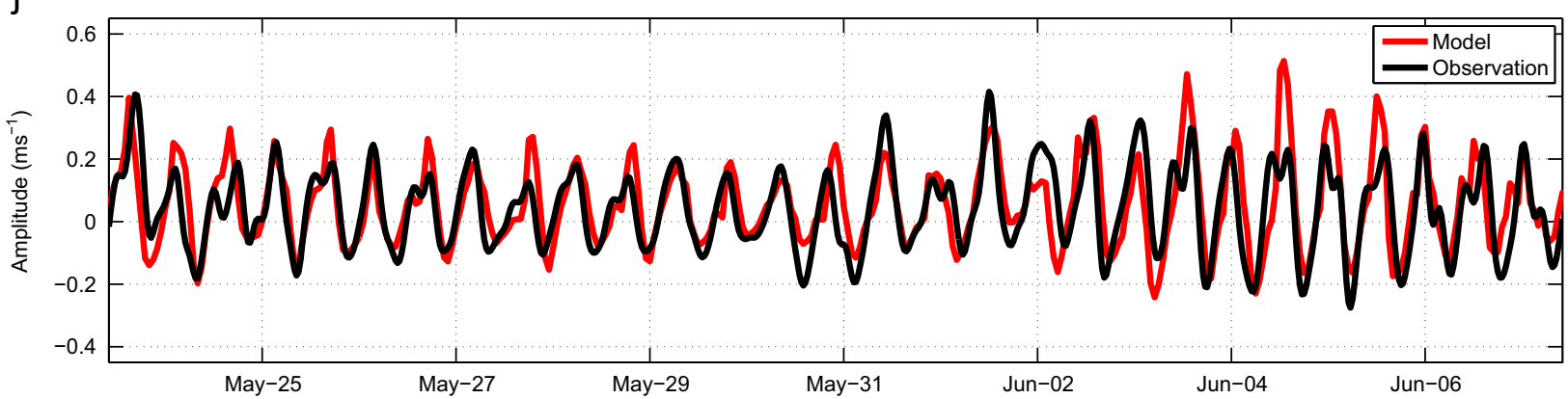

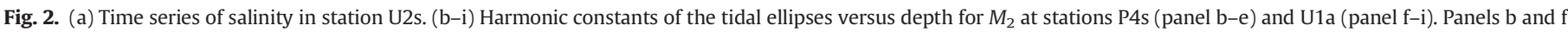

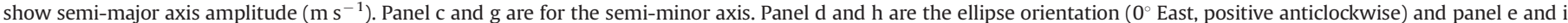

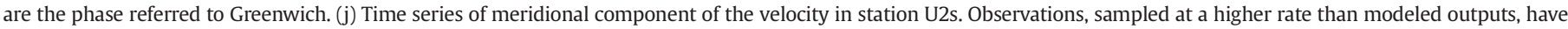
been smoothed slightly to match the hourly interval of the latter.

\section{Results and discussions}

In order to characterize the internal structure of the flow, the isohalines $S_{A t}=36.6$ and $S_{M e}=38.2$ have been chosen as proxies to define unmixed Atlantic $\left(S<S_{A t}\right)$ and Mediterranean $\left(S>S_{M e}\right)$ waters. For brevity we shall refer to Atlantic and Mediterranean layers as the portion of the water column of $S<S_{A t}$ and $S>S_{M e}$, respectively, and as interfacial the layer with $S_{A t}<S<S_{M e}$.

Fig. 3 shows the temporal mean of the depth-averaged horizontal velocity of the whole water column (barotropic velocity), 
a

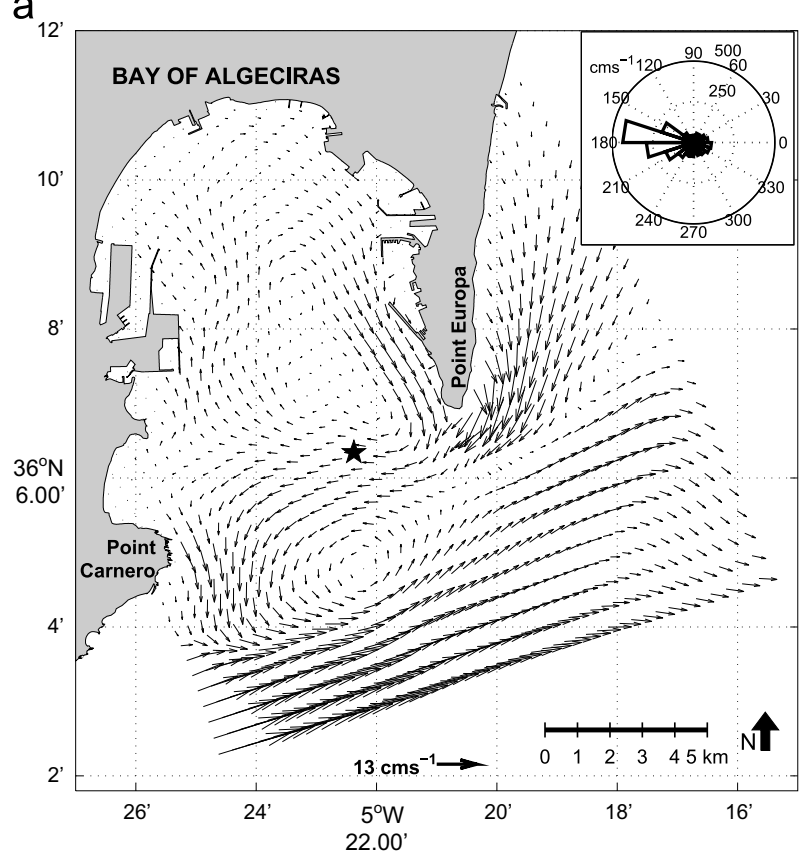

C

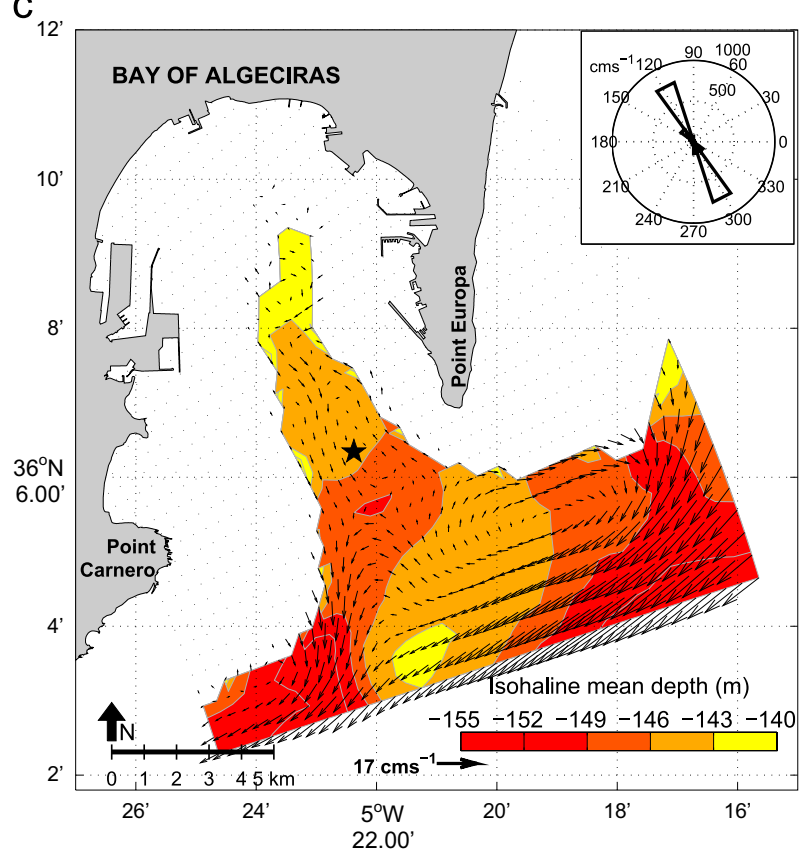

b

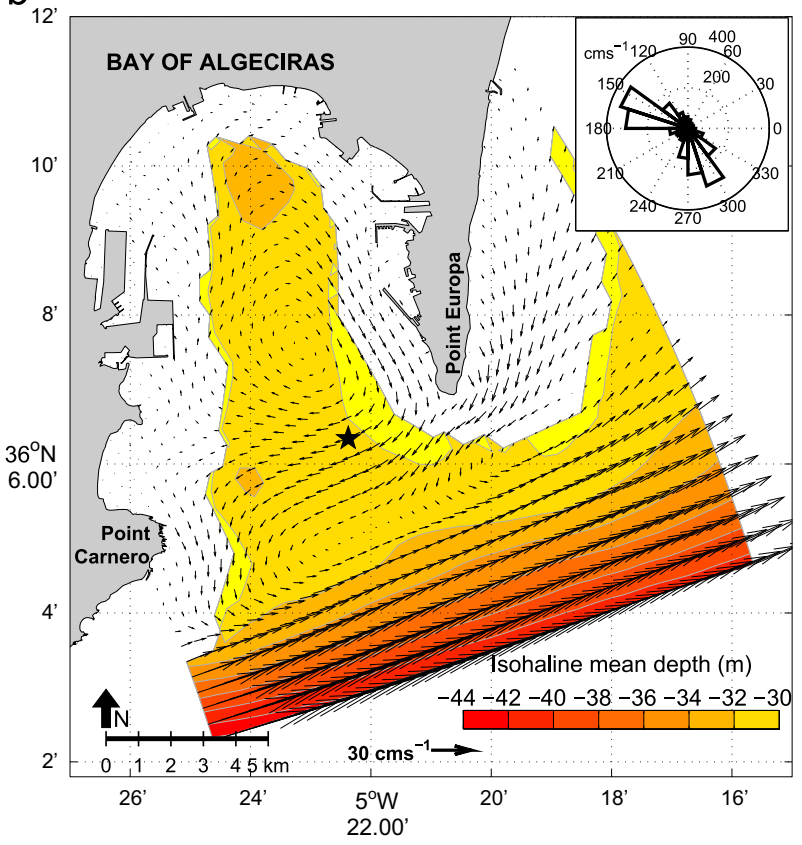

$\mathrm{d}_{12}$

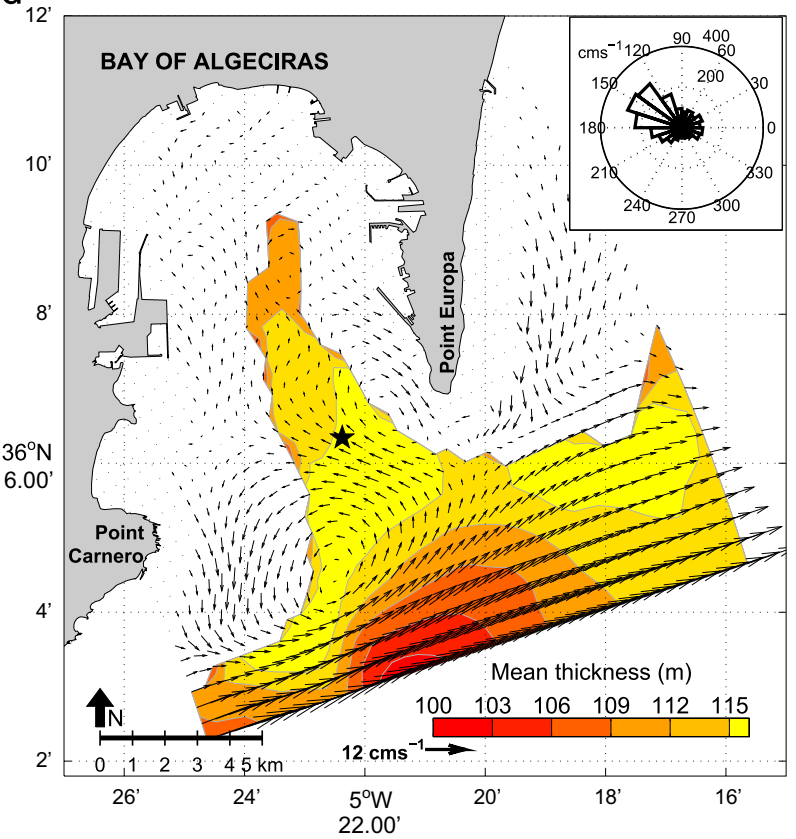

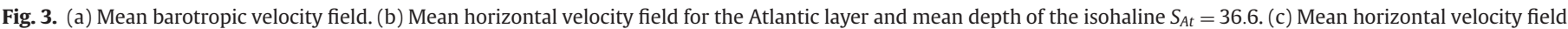

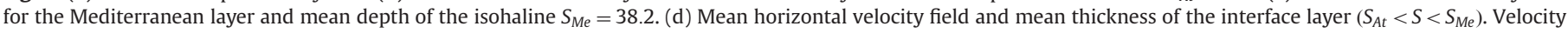
distributions at site $\mathbf{A}$ (black star) are shown in the rose diagrams in the upper-right insets.

which is weak in the Atlantic, Mediterranean and interfacial layers, inside the bay. The mean barotropic velocity (Fig. 3a) shows a pattern with prevailing eastward circulation outside the bay. A slightly intensified southward current along its (inner) eastern boundary merges also with the southward flow along the eastern flank of Gibraltar rock in the Alboran Sea. A weak anticyclonic eddy inside the bay and a second cyclonic eddy off its mouth are the most visible structures. The rose diagram shows a prevailing westward current along the mouth. In most cases, the velocities are very low, with maximum values hardly exceeding $10 \mathrm{~cm} \mathrm{~s}^{-1}$ near the Gibraltar rock. The mean circulation of the Atlantic layer (Fig. 3b) is similar to the barotropic field, although the averaged velocity inside the bay is higher (maximum values close to
$20 \mathrm{~cm} \mathrm{~s}^{-1}$ ). Away from the bay, in the strait's main channel, the velocity increases steeply, revealing the presence of the inflowing Atlantic jet. The depth-averaged velocities of the Mediterranean layer (Fig. 3c) are even weaker inside the bay, with values rarely exceeding $5 \mathrm{~cm} \mathrm{~s}^{-1}$. Again, the velocity increases greatly to the south in the open channel to match the speed of the Mediterranean outflow moving westward to the Atlantic Ocean. The interfacial layer (Fig. 3d) shows a clear cyclonic eddy in front of the mouth, which seems to be driven by the underlying Mediterranean layer (see Fig. 3c), while the velocities inside the bay are also very weak with peak values that hardly exceed $5 \mathrm{~cm} \mathrm{~s}^{-1}$.

The distribution of the horizontal velocity displayed by the rose diagrams in point A shows a marked bi-directionality in the 
Atlantic and Mediterranean layers (insets in Figs. 3b and c), with the prevailing directions oriented along the main axis of the bay and a sharing of $50 \%$ in the frequency distribution. Such bimodal distribution clearly suggests the importance of the periodic tidal forcing on the currents, which gives a nearly null temporal mean. Therefore, the mean is not useful to describe the periodic circulation of the bay that would be mainly determined by tides.

The mean depth of $S_{A t}$ (Fig. 3b) is rather constant $(30 \pm 1 \mathrm{~m})$, whereas $S_{M e}$ slopes up slightly toward the head of the bay, which would provide the pressure gradient to drive the mean seaward flow observed in Fig. 3c. Accordingly, the interface layer thickness increases from $\sim 108 \mathrm{~m}$ in the head to $\sim 115 \mathrm{~m}$ in the mouth of the bay (Fig. 3d).

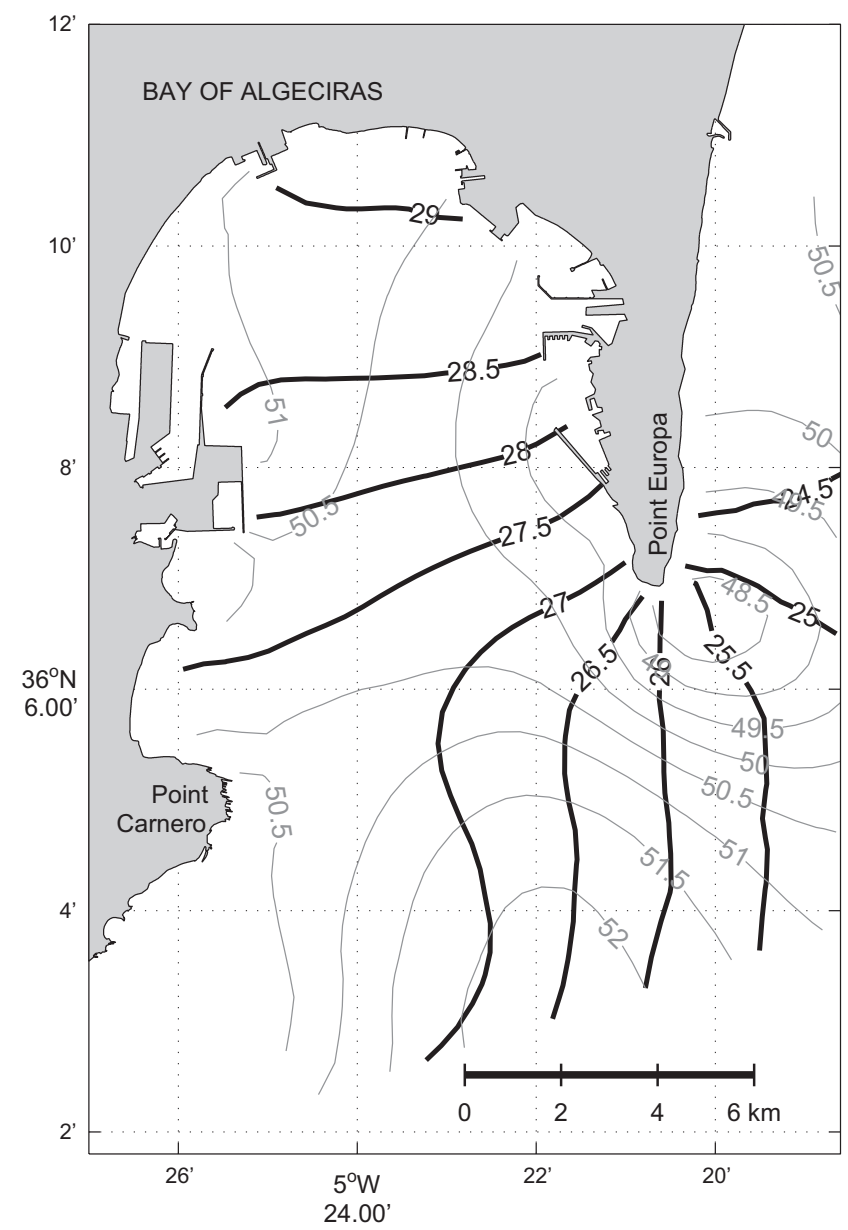

Fig. 4. Tidal chart of SSH for $M_{2}$. Thick solid lines are co-range lines (cm), and thin lines are phases (in degrees, referred to Greenwich meridian).

\subsection{Barotropic $M_{2}$ tide}

Fig. 4 shows the $M_{2}$ tidal chart of the SSH. The virtually constant phase indicates no propagation of the barotropic tide in the bay, while the amplitude reveals a very slight increase of the oscillations toward the head. The chart also shows a curious pattern around Point Europa with the co-range lines turning around the cape, recalling a refraction (with likely a complementary contribution by diffraction) pattern of the tidal wave already mentioned in Álvarez et al. (2011).

As indicated in Section 3.1, the vertically integrated velocity is nearly in quadrature with SSH (see also Table 3), which suggest a standing wave pattern, a result that is strongly supported by the standing wave nature of the external tide in the Strait of Gibraltar to which the external tide in the bay would be coupled. Nevertheless, this $90^{\circ}$ phase lag between SSH and currents also happens in short tidally driven estuaries (those where $k L \ll 1, k$ being the wavenumber and $L$ the length of the basin; the bay of Algeciras amply fulfills this condition) without invoking the existence of standing waves, as Friedrichs (2010) shows. Whatever the case, the point is not of much concern since tidal motions are dominated by the internal tide as it is shown next.

\subsection{Internal tide}

The percentage of variance of the velocity field accounted for tides is about $47 \%$, much less than the variance explained in $\mathrm{SSH}$ analysis. Even so, tides explain nearly half the variability of the currents in the bay, which is a high percentage considering the influence of other important external agents on the internal variability of the velocity field, meteorological forcing in particular.

The internal structure is displayed in Fig. 5, which shows the $M_{2}$ tidal amplitude and phase of the meridional component of the velocity in the cross-bay section between Point Carnero and Point Europe (CE section hereinafter) and in the longitudinal section between the mouth and the head of the bay (MH section hereinafter). The co-phase map in CE section (Fig. 5a) shows a phase increase from the deeper layer, where the phase is rather constant around $120^{\circ}$, to the upper layer, where it reaches a nearly constant value of around $300^{\circ}$. The transition from one value to the other takes place quickly across a thin layer located at around $80 \mathrm{~m}$ depth that coincides with the zone of minimum (nearly null, in fact) values of the velocity amplitude (Fig. 5b). This layer resides inside the defined interfacial layer, which explains the lack of bimodality observed in the rose diagram of Fig. $3 \mathrm{~d}$ when compared to the clear bimodality in the Atlantic and Mediterranean layers (Fig. $3 \mathrm{~b}$ and c).

The above depicted structure is archetypical of a first-mode internal tide with the zero-crossing (change of phase of the

Table 3

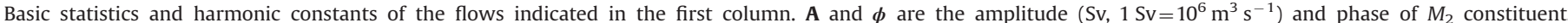

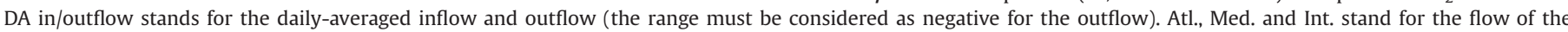

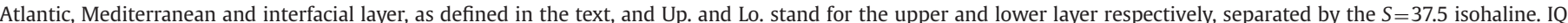

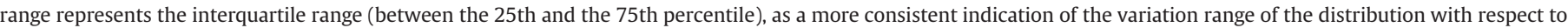
the min-max range.

\begin{tabular}{|c|c|c|c|c|}
\hline Flow & $A(S v)$ & $\phi\left({ }^{\circ}\right)$ & IQ range (Sv) & Min-max (Sv) \\
\hline Tot. inflow & - & - & $(4.6-7.7) \times 10^{-2}$ & $(2.1-16) \times 10^{-2}$ \\
\hline Tot. outflow & - & - & $-(7.7-4.6) \times 10^{-2}$ & $-(15-2) \times 10^{-2}$ \\
\hline Net flow & $(2.7 \pm 0.2) \times 10^{-3}$ & $311 \pm 4$ & - & - \\
\hline DA in/outflow & - & - & $(5.3-7.1) \times 10^{-2}$ & $(3.9-9.1) \times 10^{-2}$ \\
\hline Atl. flow & $(3.5 \pm 0.9) \times 10^{-2}$ & $286 \pm 14$ & - & - \\
\hline Med. flow & $(4.1 \pm 0.9) \times 10^{-2}$ & $116 \pm 13$ & - & - \\
\hline Int. flow & $(1.1 \pm 0.7) \times 10^{-2}$ & $334 \pm 40$ & - & - \\
\hline Up. flow & $(6.1 \pm 0.9) \times 10^{-2}$ & $301 \pm 9$ & - & - \\
\hline Lo. flow & $(5.8 \pm 1) \times 10^{-2}$ & $120 \pm 9$ & - & - \\
\hline
\end{tabular}


a

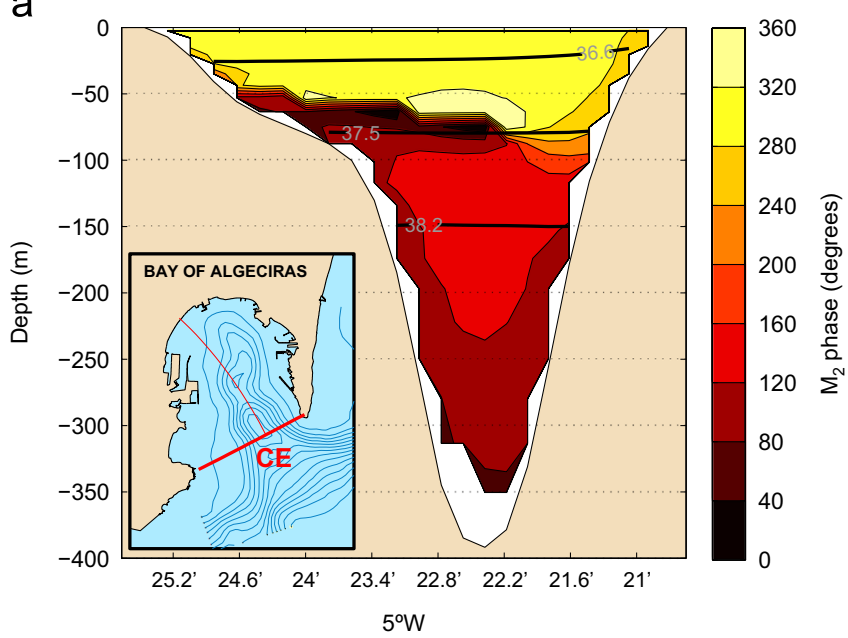

C

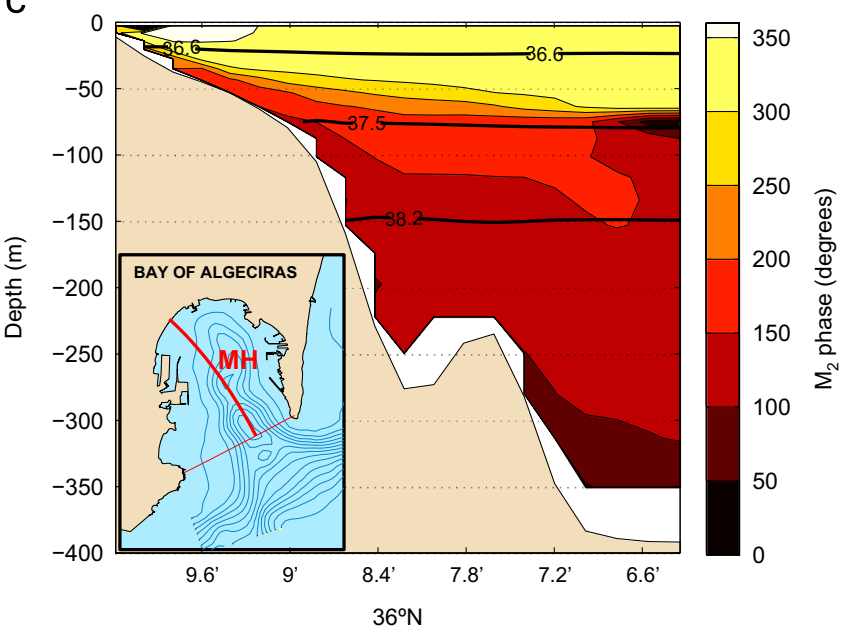

b

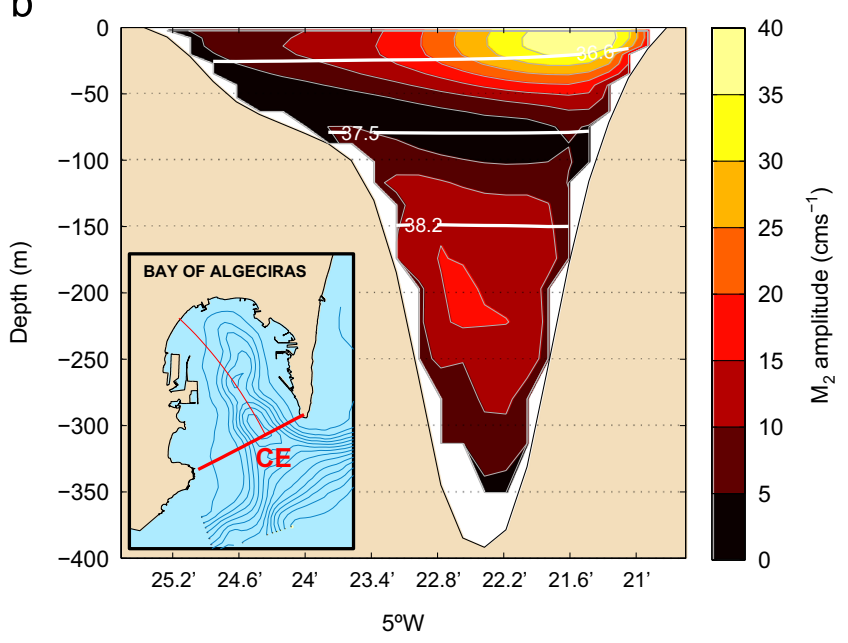

d

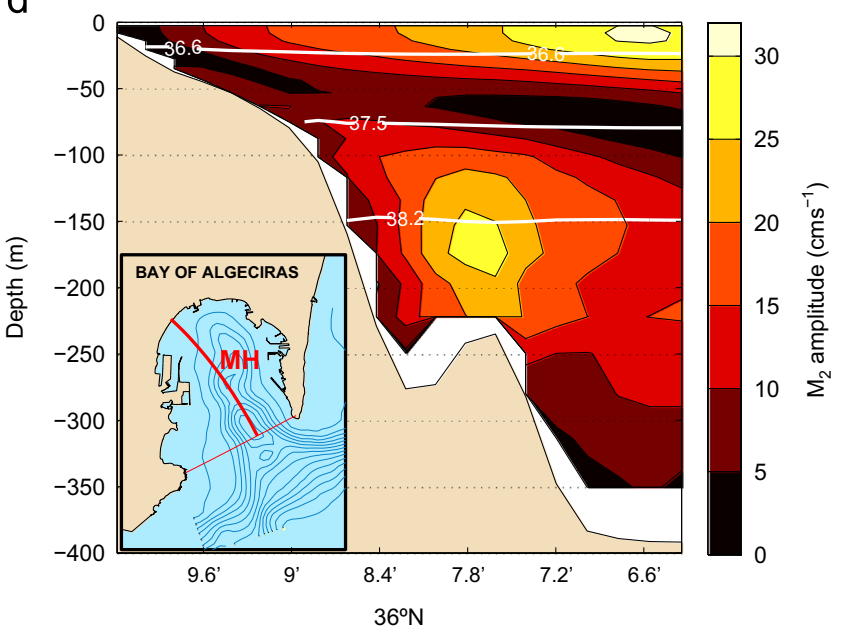

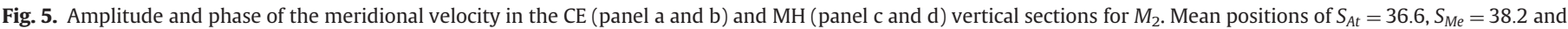
$S=37.5$ are plotted for reference.

current) located at the depth of minimum amplitude. Notice that this depth coincides roughly with the $S=37.5$ isohaline, the reason for which this isohaline will be considered as a material interface of the internal tide in the present study. The baroclinic pattern is maintained along the $\mathrm{MH}$ section, where the phase opposition between the surface and deep layers is again observed throughout the section (Fig. 5c). As in CE, the layer of strong phase gradient that separates the two regions coincides with the layer of minimum amplitude (Fig. 5d), and both of them slope up to the north of the bay, forced likely by the progressive raising of the seafloor. The relatively flat isohaline $S=37.5$ still represents the interface reasonably well in the $\mathrm{MH}$ section, although it diverges progressively from the minimum amplitude/strong phase gradient layer because of the northward tilt of the latter (Fig. 6b).

In the deep Mediterranean layer the $M_{2}$ amplitude is slightly enhanced in the west half of CE section (Fig. 5b) and significantly increased in the middle of $\mathrm{MH}$ section (Fig. 5d) above the slight seafloor elevation at the center of the bay (see Fig. 1), which suggests a topographically induced spatial acceleration of the current (as in Bernoulli dynamics). In the Atlantic layer the pattern is somewhat different, with the $M_{2}$ amplitude increasing from west to east (Fig. 5b) and from the mouth to the head (Fig. 5d). While the latter is an expected result because of volume conservation, the former is less intuitive and it is related to the overall pattern of the $M_{2}$ internal tide in the bay.
Fig. 6a presents the tidal chart of the $S=37.5$ interface for $M_{2}$. Even when the explained variance is low ( $\sim 30 \%$, Fig. $6 b)$, the depicted pattern seems robust and suggests a refraction of the internal tide. The co-phase lines rotate anticlockwise around this point and the co-range lines increase outward from this point, which implies stronger tidal currents along the eastern boundary of the bay, as shown in Fig. 5b. This distribution recalls the structure of the classical amphidromic systems in the oceanic barotropic tide forced by the Earth rotation, with the amphidromic point located landward and not within the sea in this case. We shall refer this structure as an amphidromic-like system throughout the paper.

The bathymetry of the bay is likely to be responsible for the existence of this refraction, although contribution from rotation cannot be disregarded. Fig. 1 shows that the western half of the bay is occupied by a wide continental shelf that in turn affects the phase speed $c_{i}$ of the baroclinic modes: the greater the water depth the faster the $c_{i}$. In case of a two layer fluid with a density difference $\Delta \rho$ and thickness $H_{1}$ and $H_{2}=H-H_{1}$ for the upper and lower layer, respectively ( $H$ the total water depth), the linear theory of internal waves prescribes a phase speed for the internal mode (Gill, 1982, p. 128, for instance)

$c_{1}=\sqrt{\left(H_{1}-\frac{H_{1}^{2}}{H}\right) \frac{\Delta \rho}{\rho_{0}} g}$ 

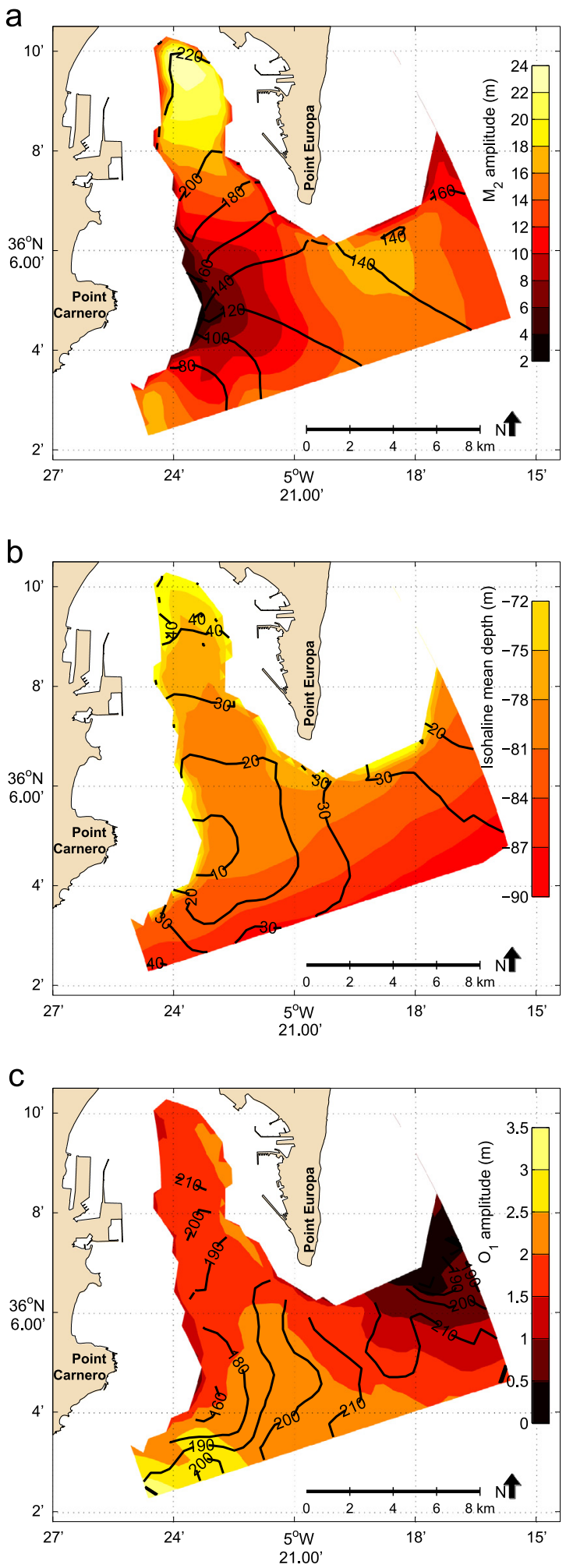

Fig. 6. (a) Tidal chart of $S=37.5$ isohaline oscillations for $M_{2}$. Black lines are for phase (referred to Greenwich) and colored contours for amplitude (m). (b) Mean depth of the $S=37.5$ isohaline (colored contours) and explained variance (black lines, percentage) of the harmonic analysis of $S=37.5$. (c) Same as panel (a) for the $O_{1}$ diurnal constituent. (For interpretation of the references to color in this figure legend, the reader is referred to the web version of this paper.)

where $\rho_{0}$ is a reference density and $g$ is the gravitational acceleration. Reasonable values for $H_{1}$ and $\Delta \rho$ for fitting a continuously stratified fluid by a two layer system would be $H_{1}=80 \mathrm{~m}$ (Fig. 6b) and
$\Delta \rho=2 \mathrm{~kg} \mathrm{~m}^{-3}$, which gives $c_{1} \approx 0.5 \mathrm{~m} \mathrm{~s}^{-1}$ if $H \approx 100 \mathrm{~m}$ (representative of the outer continental shelf area) and $c_{1} \approx 1 \mathrm{~m} \mathrm{~s}^{-1}$ if $H \approx 300 \mathrm{~m}$ (representative of the deeper area of the bay). This substantial difference in phase speed would give rise to a rotating pattern of co-phase lines like that in Fig. 6a.

On the other hand, the first internal radius of deformation, $r_{1}=c_{1} / f\left(f\right.$ the inertial frequency, which is $f=8.55 \times 10^{-5} \mathrm{~s}^{-1}$ at $36^{\circ}$ latitude), is about $10 \mathrm{~km}$ for the wave speeds estimated above and, therefore, comparable to the width of the bay, which in turn would suggest a non-negligible influence of the Earth rotation in the observed amphidromic-like system, whose most remarkable result would be the outward increase of the tidal velocity amplitude. The question of whether refraction prevails on rotation or vice versa is out of the scope of this study and is not addressed here.

Inside the bay, the co-phase lines are organized more uniformly and denote northward propagation of the $M_{2}$ internal tide whose phase speed, estimated as $c=(\Delta y / \Delta \phi) \cdot \omega_{M_{2}}(\Delta \phi$ being the phase difference between 2 points separated $\Delta y$, and $\omega_{M_{2}}$ the $M_{2}$ frequency), and wavelength, $\lambda=2 \pi c / \omega_{M_{2}}$, would be $c \approx 1 \mathrm{~m} \mathrm{~s}^{-1}$ and $\lambda \approx 45 \mathrm{~km}$, respectively ( $\Delta \phi \approx 60^{\circ}$ for $\Delta y \approx 7.5 \mathrm{~km}$, see Fig. $6 \mathrm{a}$ ). This phase speed coincides fairly well with the value of $0.9 \mathrm{~m} \mathrm{~s}^{-1}$ obtained for the first baroclinic mode of the continuously stratified system defined by the mean density profile at the mouth of the bay (see Kundu et al., 2011, Eq. (14.66)).

As it could be expected, and as long as the actual internal tide is dominated by the first baroclinic mode, this wave speed coincides well with the internal mode speed of the two-layer ocean for $H \approx 300 \mathrm{~m}$ in Eq. (3).

The north-south dimension of the bay (around $10-12 \mathrm{~km}$ ) coincides with $\lambda / 4$ and suggests the possibility of a quarter-wave resonance. Two main issues support this hypothesis: (1) the enhanced amplitude of the interface oscillation at the head of the bay, which nearly doubles the amplitude at the mouth (co-range lines in Fig. 6a) and (2) the near quadrature phase shift of the interface oscillation between the inner bay and its mouth. Furthermore, the pattern in Fig. 6a is representative for semidiurnal constituents only ( $S_{2}$ chart, not presented here, shows the same pattern as $M_{2}$, although with smaller amplitudes) and not for diurnal constituents, which presents a very different structure. $O_{1}$ map in Fig. 6c does not show any increase of amplitude toward the head of the bay; rather the contrary, amplitudes appear to be slightly greater at the mouth. The amplification is frequencydependent (a typical characteristic of resonance) and supports the existence of the hypothesized quarter-wave resonance for semidiurnal frequencies. It should be noted incidentally that $O_{1}$ amplitudes in Fig. 6c (which are representative of other diurnal constituents) are one order of magnitude smaller than those of $M_{2}$ in Fig. 6a, indicating that tidal flow is basically driven by the semidiurnal species, by $M_{2}$ in particular.

Fig. 7 shows the vertical oscillations of $S_{A t}, S=37.5$ and $S_{M e}$ isohalines at the mouth of the bay (site A, see Fig. 1). Their mean depths are $23 \mathrm{~m}, 80 \mathrm{~m}$ and $148 \mathrm{~m}$ (Fig. 5a) and all of them exhibit semidiurnal $\left(M_{2}\right)$ oscillations that account for $10 \%, 19 \%$ and $40 \%$ of the variance, respectively. The harmonic analysis gives $M_{2}$ amplitudes of $5 \pm 2 \mathrm{~m}, 11 \pm 2 \mathrm{~m}$, and $18 \pm 4 \mathrm{~m}$, and phases of $93 \pm 12^{\circ}$, $168 \pm 8^{\circ}$ and $195 \pm 11^{\circ}$ for $S_{A t}, S=37.5$, and $S_{M e}$, respectively. The phases increase with depth, which corresponds to downward progression of the wave fronts and upward propagation of the energy.

\subsection{Tidal transport}

Fig. 8 shows the time series of the water flowing in and out of the bay. They have been computed taking only into account the sign of the meridional velocity and not the reference isohalines. 


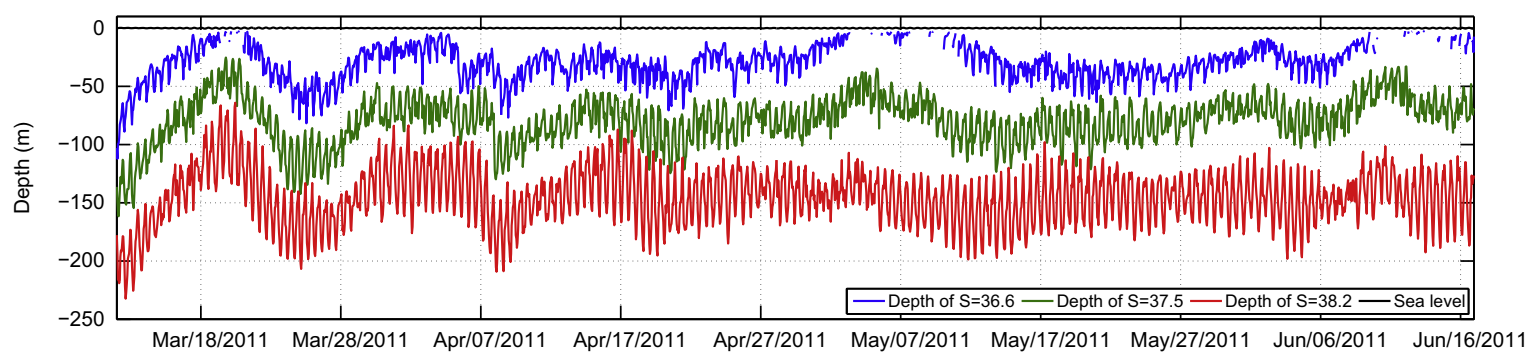

Fig. 7. Time series of the depths of the isohalines $S_{A t}=36.6, S_{M e}=38.2$ and $S=37.5$, at site $\mathbf{A}$ (see Fig. 1 for location).

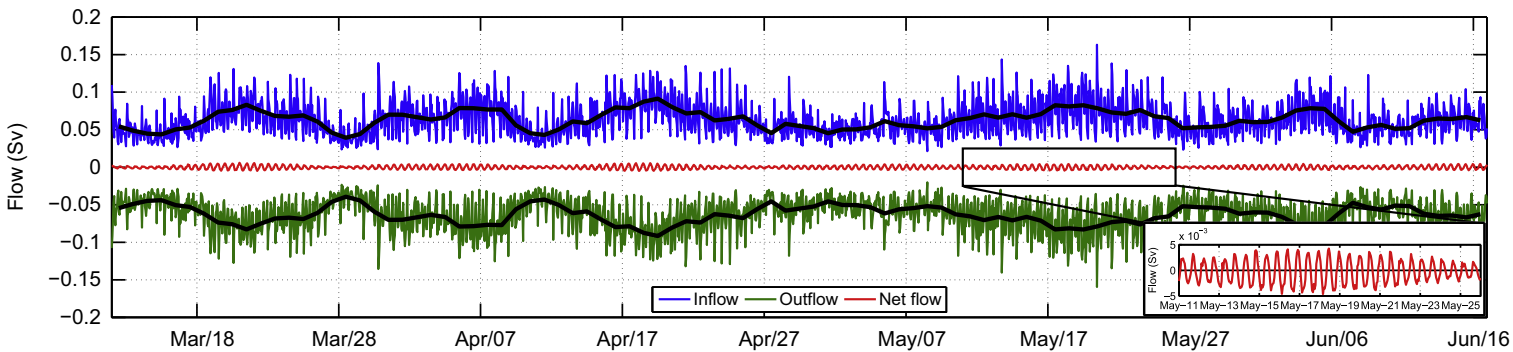

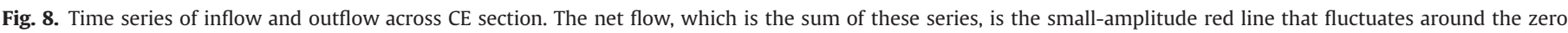

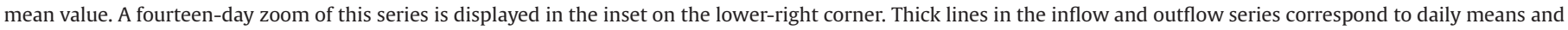
illustrate their subtidal fluctuations. (For interpretation of the references to color in this figure legend, the reader is referred to the web version of this paper.)

In other words, the computation considered that, at a given time, water parcels with positive (negative) meridional velocity are flowing into (out of) the bay and contributing to its instantaneous water budget, regardless of their salinity. The sum of these series is the net barotropic flow (inset in Fig. 8) that is much lower than any of the two flows in the summation, showing that the instantaneous water exchange through the mouth of the bay is more than one order of magnitude greater than needed to account for the vertical tide, which is balanced by the net barotropic flow uniquely.

This point is readily confirmed by continuity arguments, since SSH oscillations of the bay and the barotropic flow must verify

$A_{B}(\partial \eta / \partial t)=Q_{b t p}$

where $A_{B}$ is the surface area of the bay, $\eta$ is the sea level and $Q_{b t p}$ is the barotropic transport through CE. For $M_{2}$ tidal oscillations, Eq. (4) implies

$A_{B} \eta_{0} \omega_{M_{2}}=Q_{b t p, 0}$

where $\eta_{0}$ and $Q_{b t p, 0}$ are the amplitudes of $\mathrm{SSH}\left(\eta_{0} \approx 28 \mathrm{~cm}\right.$ inside the bay, Fig. 4) and barotropic tide $\left(Q_{b t p, 0}=2.7 \pm 0.2 \times 10^{-3} \mathrm{~Sv}\right.$, Table 3), respectively. With $A_{B}=73 \mathrm{~km}^{2}$, the LHS of Eq. (5) is $2.8 \times 10^{3} \mathrm{~m}^{3} \mathrm{~s}^{-1}$, in very good agreement with $Q_{b t p, 0}$. Moreover, the $M_{2}$ phase of the barotropic flow is $311 \pm 4^{\circ}$ (Table 3), which leads the phase of SSH by nearly $90^{\circ}$ (Fig. 4).

More interesting is the analysis of the tidal flow of the water masses defined by the reference isohalines $S_{A t}$ and $S_{M e}$, and also of the upper and lower layer transports defined using $S=37.5$. Fig. 9 shows a fragment of the time series of Atlantic, Mediterranean and interface layers together with the upper and lower layer transports across CE. While the oscillations of the Atlantic and Mediterranean layers are sinusoidally shaped and clearly in opposition (see $M_{2}$ phases in Table 3), the series corresponding to the interface layer is more irregular and shows a blurred semidiurnal periodicity. Actually, the variance accounted by the harmonic analysis in this layer is hardly $10 \%$, while it rises to $54 \%$ and $63 \%$ for the Atlantic and Mediterranean flows, respectively. The signal-to-noise ratio of $M_{2}$ amplitude in the three layers also corroborate this fact, although the most noticeable result is that the amplitude of the Atlantic and Mediterranean layers is more than one order of

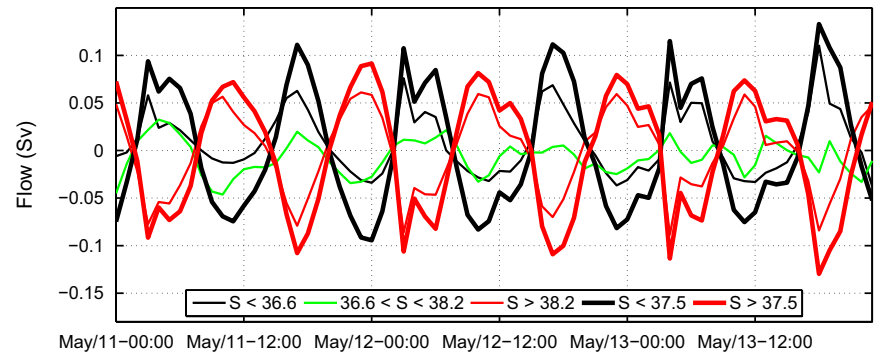

Fig. 9. Three-day time series of the Atlantic $(S<36.6)$, Mediterranean $(S>38.2)$, interface (36.6 $<S<38.2)$, upper $(S<37.5)$ and lower $(S>37.5)$ layer flows (color) style code for the different lines is explained in the legend). (For interpretation of the references to color in this figure legend, the reader is referred to the web version of this paper.)

magnitude greater than $Q_{b t p, 0}$ (Table 3). The results are even clearer considering the upper and lower layer transports, which shows great similitude with the Atlantic and Mediterranean layers, respectively, although with greater amplitude, a fact also reflected in the harmonic constants in Table 3 (note that, within this decomposition, the interface layer does not exist because it is now part of either the upper or the lower layer or both).

These results highlight the prevalence of the baroclinic tidal exchange against the barotropic tide. The phase of the barotropic tide is much closer to the phase of the Atlantic layer than to the phase of the Mediterranean layer, suggesting that the bay is filled with Atlantic water during the rising tide (flood) and emptied during the falling tide (ebb). By continuity the Mediterranean water must behave in the opposite way, flowing out of the bay during the flood and in during the ebb.

The meridional pattern of the baroclinic tide is better depicted using the meridional stream function (MSF) defined as the zonally integrated transport computed from CE to the innermost available section according to Pacanowski and Griffies (1999)

$\psi(\phi, z, t)=\int_{0}^{z} \int_{\xi_{1}}^{\xi_{2}} v(\phi, \xi, z, t) \cdot d z d \xi$ 
It represents the accumulated transport integrated zonally from one side of the bay $\left(\xi_{1}\right)$ to the other $\left(\xi_{2}\right)$ and from the sea surface to depth $z$, and illustrates how the baroclinic tide behaves along the axis of the bay. The $z$-derivative of MSF gives the horizontal meridional transport per unit depth $\left(v_{H}\right)$ while its $y$-derivative gives the vertical transport per surface unit width according to

$v_{H}=-\partial \psi / \partial z ; \quad w_{H}=\partial \psi / \partial y$

Fig. 10 displays the $M_{2}$ tidal chart of MSF and shows the attenuation of the tidal transport (Fig. 10a) toward the head of the bay. The dashed line corresponds to $\partial \psi / \partial z=0$ and separates the regions where, according to Eq. (7), the horizontal transport $v_{H}$ changes sign (see gray arrows). The line slopes upward to the north and indicates that the isohaline $S=37.5$ is a good proxy of the interface near the mouth of the bay, but it is not so much in its northern part, where the isohaline lies beneath $\partial \psi / \partial z=0$ by less than $50 \mathrm{~m}$. The $M_{2}$ phase of MSF (Fig. 10b) increases horizontally from the mouth to the head of the bay, indicating propagation in this direction. Actually the phase difference between both ends of the bay is around $60^{\circ}$, matching the pattern of the internal oscillation presented in Fig. 6a. The phase also increases in the vertical from the lower to the upper layer, although the phase difference at a given latitude is very small (Fig. 10b), suggesting that the circulation pattern is mainly determined by the spatial distribution of amplitude. Actually, during the flood (rising) tide, the tidal transport would be represented by the light gray arrows
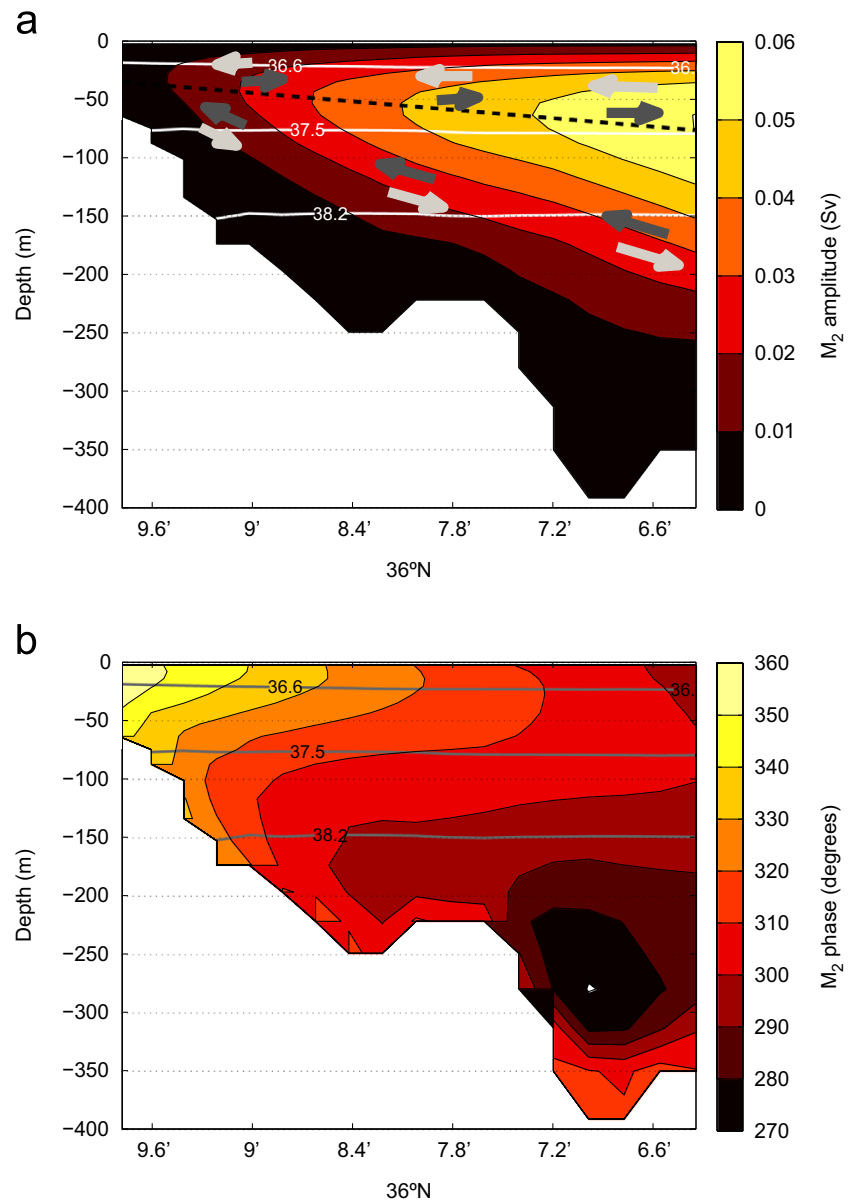

Fig. 10. Amplitude (a) and phase (b) of the $M_{2}$ constituent for MSF. Dashed line in panel (a) connects the points where $\partial \psi / \partial z=0$ (see the text for details). Light and dark gray arrows indicate the circulation during flood and ebb tide, respectively. Isohalines $S_{A t}, S=37.5$ and $S_{M e}$ are plotted for reference. in Fig. 10a while the pattern reverses during the ebb (dark gray arrows).

\section{Summary and conclusions}

A high-resolution numerical model (MITgcm) has been applied to the study of the tidal circulation, focusing on the $M_{2}$ constituent, in the Bay of Algeciras, an embayment of nonnegligible dimensions adjoined to the eastern part of the Strait of Gibraltar. The model has been validated using a comprehensive set of measurements collected in different locations of the bay during two field experiments carried out in spring and autumn of year 2011.

The $M_{2}$ barotropic tides inside the bay share the same characteristics of a standing wave as the external tide in the Strait of Gibraltar area, with a barotropic tidal flow of $2.7 \times 10^{-3} \mathrm{~Sv}$ amplitude (Table 3 ) entering the bay during the flood, which produces a tidal SSH oscillation of about $28 \mathrm{~cm}$ amplitude (Fig. 4) delayed by $90^{\circ}$ with respect to the tidal barotropic flow. Very similar spatial patterns have been obtained for other semidiurnal constituents ( $S_{2}$, figure not presented) with the expected reduction in amplitude. Diurnal constituents show amplitudes one order of magnitude smaller than $M_{2}$ (comparison of Fig. 6a and c provides an illustrative example) and have not been considered in this study.

The barotropic tidal transport results from the sum of two much larger baroclinic transports that affect the Atlantic $\left(S<S_{A t}\right)$ or upper $(S<37.5)$ layers and the Mediterranean $\left(S>S_{M e}\right)$ or lower $(S>37.5)$ layers. The analysis of the internal oscillations of isohalines (Fig. 6) suggests the possibility of a quarter-wave resonance given that the north-south length of the bay matches $\lambda / 4, \lambda$ being the wavelength of the internal tide. Internal co-tidal distributions at the mouth of the bay resemble a virtual internal amphidromic point (Fig. 6a), which is probably driven by the joint effect of refraction in the shallow continental shelf at the western half of the bay and the Earth rotation. This structure leads to a nearly anti-phase relationship between the internal oscillations inside and outside of the bay and strongly suggests that the internal tide observed in the bay is not locally generated but radiated in from outside. In other words, the large internal tide of the strait would force the baroclinic tide inside the bay. This is an obvious and expected result, but there are some details not so intuitive that deserve further comment.

The internal tide in the strait behaves in such a manner that the isohalines are displaced upward during the rising tide, and downward during the falling tide (García-Lafuente et al., 1990, 2013; Sánchez-Román et al., 2009, 2012). However, in the bay this scheme is inverted: the isohalines are displaced downward during the rising tide, evacuating Mediterranean water from the bay that joins the tidal stream flowing westward along the main channel of the strait, while the Atlantic water invades the bay and makes the upper layer thicker. During the falling tide, part of the Mediterranean water, which is flowing eastward during this tidal semi-cycle, enters the bay and makes the lower layer thicker, forcing the Atlantic water in the upper layer to move outward.

The baroclinic transport through the mouth of the bay, at both tidal and sub-tidal time scales, exceeds by more than one order of magnitude the barotropic flow. At tidal time-scales the sum of inflow and outflow gives the relatively small barotropic time series (inset in Fig. 8) that accounts for the SSH tidal oscillations, while at sub-tidal time-scales (thick lines Fig. 8) the barotropic transport is almost null (except for the very small oscillations, one order of magnitude smaller than the net tidal flow, induced by meteorological forcing) in accordance with the long-term conservation of 
the volume of the bay. The relative large baroclinic flow suggests that it plays a much more important role than the barotropic contribution for the water renewal of the bay. In this regards it is interesting to note the clear fortnightly signal in the low-passed series, with values in spring tides that can be twice those in neap tides, suggesting an important fortnightly modulation of the water renewal of the bay.

The Bay of Algeciras can be considered as a small transient reservoir of Mediterranean and Atlantic waters driven by the baroclinic tidal forcing imposed by the Strait of Gibraltar at its open boundary. The basin can store about 1 billion cubic meters of Atlantic and/or Mediterranean water, with tidal periodicity. Of particular importance is the temporal storage of the nutrient-rich Mediterranean water that can approach the surface at the head of the bay during the ebb tide if suitable meteorological conditions are simultaneously met. Hints of such events can be seen in Fig. 7 around March 18, May 5-10, or June 8-14, 2011, when the isohaline $S_{A t}$ intersects the free surface repeatedly. Sub-tidal circulation, however, is not dealt with in this study since it is the topic of a separate on-going study (Sánchez-Garrido et al., in preparation).

\section{Acknowledgments}

The model runs and the experimental data analyzed in this work have been carried out within the frame of SAMPA project (http://sampa-apba.puertos.es/), funded by the Spanish institutions of Autoridad Portuaria Bahía de Algeciras and Puertos del Estado. Partial financial support was provided by the Spanish funded INGRES project (CTM2010-21229-C02-01/MAR, Ministerio de Economía y Competitividad). CN acknowledges the pre-doc fellowship BES-2011-043421 and CC acknowledges the financial support within the action CTM2008-04150E. We are also grateful to the University of Granada (Spain) and the Spanish Instituto Hidrográfico de la Marina for their support in the field experiments. Special thanks to the crew of Calima ship from the Autoridad Portuaria Bahía de Algeciras that gave support during the field experiments. The first author wants to personally thank Ms. Lynn Mitchell for her friendly support in the revision of the work. This is the publication no. 37 from CEIMAR Publication Series.

\section{Appendix A. Supplementary material}

Supplementary data associated with this article can be found in the online version at http://dx.doi.org/10.1016/j.csr.2013.11.002.

\section{References}

Álvarez, O., González, C.J., Mañanes, R., López, L., Bruno, M., Izquierdo, A., GómezEnri, J., Forero, M., 2011. Analysis of short-period internal waves using waveinduced surface displacement: a three-dimensional model approach in Algeciras Bay and the Strait of Gibraltar. J. Geophys. Res. 116 http://dx.doi.org/10. 1029/2011JC007393.

Álvarez-Fanjul, E., Pérez-Gómez, B., Rodríguez-Sánchez-Arévalo, I., 2001. Nivmar: a storm surge forecasting system for Spanish waters. Sci. Mar. 65.

Armi, L., Farmer, D.M., 1988. The Flow of Mediterranean Water Through the Strait of Gibraltar. Progress in Oceanography. Pergamon Press http://dx.doi.org/10.1016 0079-6611(88)90055-9.

Candela, J., Winan, C., Ruiz, A., 1990. Tides in the Strait of Gibraltar. J. Geophys. Res. 95, 7313-7335 http://dx.doi.org/10.1029/JC095iC05p07313.

Candela, J., Winant, C., Bryden, H.L., 1989. Meteorologically forced subinertial flows through the Strait of Gibraltar. J. Geophys. Res. 94, 12667-12679 http://dx.doi. org/10.1029/JC094iC09p12667.

Carrere, L., Lyard, F., 2003. Modelling the barotropic response of the global ocean to atmospheric wind and pressure forcing-comparisons with observations. Geophys. Res. Lett. 30, 1-8 http://dx.doi.org/10.1029/2002GL016473.
Carter, G.S., Merrield, M.A., 2007. Open boundary conditions for regional tidal simulations. Ocean Modelling 18, 194-209 http://dx.doi.org/10.1016/j.ocemod. 2007.04.003.

Cats, G., Wolters, L., 1996. The Hirlam project. Comput. Sci. Eng. 3, 4-7 http://dx.doi, org/10.1109/99.556505.

Defant, A., 1960. Physical Oceanography, vol. 2. Pergamon Press, New York, USA.

Friedrichs, C.T., 2010. Barotropic tides in channelized estuaries. In: Valle-Levinson, A. (Ed.), Contemporary Issues in Estuary Physics. Cambridge University Press, Cambridge, United Kingdom, pp. 27-61.

García-Lafuente, J., Almazan, J.L., Castillejo, F., Khribeche, A., Hakimi, A., 1990. Sea level in the Strait of Gibraltar: tides. Int. Hydrogr. Rev. LXVII, 111-130.

García-Lafuente, J., Bruque Pozas, E., Sánchez-Garrido, J.C., Sannino, G., Sammartino, S., 2013. The interface mixing layer and the tidal dynamics at the eastern part of the Strait of Gibraltar. J. Mar. Syst. 117-118, 31-42 http://dx.doi.org/10.1016/j. jmarsys.2013.02.014.

García-Lafuente, J., Álvarez Fanjul, E., Vargas, J., Ratsimandresy, A.W., 2002. Subinertial variability in the flow through the Strait of Gibraltar. J. Geophys. Res. 107 http://dx.doi.org/10.1029/2001JC001104.

García Lafuente, J., Vargas, J.M., Plaza, F., Sarhan, T., Candela, J., Bascheck, B., 2000. Tide at the eastern section of the Strait of Gibraltar. J. Geophys. Res. 105, 14197-14213 http://dx.doi.org/10.1029/2000JC900007.

GEBCO, 2003. IOC, IHO and BODC, 2003. Centenary Edition of the GEBCO Digital Atlas, Published on CD-ROM on Behalf of the Intergovernmental Oceanographic Commission and the International Hydrographic Organization as part of the General Bathymetric Chart of the Oceans, British Oceanographic Data Centre, Liverpool, UK.

Gill, A.E., 1982. Atmosphere-Oceans Dynamics. International Geophysics Series. Academic Press, Inc., London.

Izquierdo, A., Tejedor, L., Sein, D.V., Backhaus, J.O., Brandt, P., Rubino, A., Kagan, B.A., 2001. Control variability and internal bore evolution in the strait of Gibraltar: a 2-D two-layer model study. Estuarine Coastal Shelf Sci. 53, 637-651 http://dx. doi.org/10.1006/ecss.2000.0706.

Kundu, P.K., Cohen, I.M., Dowling, D.R., 2011. Fluid Mechanics, fifth edition. Academic Press, Inc., London.

Legg, S., Hallberg, R.W., Girton, J.B., 2006. Comparison of entrainment in overflows simulated by z-coordinate, isopycnal and non-hydrostatic models. Ocean Modelling 11, 69-97 http://dx.doi.org/10.1016/j.ocemod.2004.11.006.

Leith, C.E., 1968. Diffusion approximation for two-dimensional turbulence. Phys, Fluids 11, 671-672 http://link.aip.org/link/doi/10.1063/1.1691968.

Marshall, J., Adcroft, A., Hill, C., Perelman, L., Heisey, C., 1997. A finite-volume, incompressible Navier Stokes model for studies of the ocean on parallel computers. J. Geophys. Res. 102, 5753-5766 http://dx.doi.org/10.1029/96JC02775.

Oddo, P., Adani, M., Pinardi, N., Fratianni, C., Tonani, M., Pettenuzzo, D., 2009. A nested Atlantic-Mediterranean Sea general circulation model for operational forecasting. Ocean Sci. 5, 461-473 http://dx.doi.org/10.5194/os-5-461-2009.

Pacanowski, R.C., Griffies, S.M., 1999. The MOM3 Manual, GFDL Ocean Group. Technical Report 4. NOAA/Geophysical Fluid Dynamics Laboratory. Princeton, NJ.

Pacanowski, R.C., Philander, S.G.H., 1981. Parameterization of vertical mixing in numerical models of tropical oceans. J. Phys. Oceanogr. 11, 1443-1451.

Pawlowicz, R., Beardsley, B., Lentz, S., 2002. Classical tidal harmonic analysis including error estimates in MATLAB using T_TIDE. Comput. Geosci. 28, 929-937 http://dx.doi.org/10.1016/S0098-3004(02)00013-4.

Periáñez, R., 2012. Modelling the environmental behaviour of pollutants in Algeciras Bay (south Spain). Mar. Pollut. Bull. 64, 221-232 http://dx.doi.org/ 10.1016/j.marpolbul.2011.11.030.

Sánchez-Garrido, J.C., García Lafuente, J., Criado Aldeanueva, F., Baquerizo, A., Sannino, G., 2008. Time-spatial variability observed in velocity of propagation of the internal bore in the Strait of Gibraltar. J. Geophys. Res.: Oceans 113 http:// dx.doi.org/10.1029/2007JC004624.

Sánchez-Garrido, J.C., García Lafuente, J., Sammartino, S., Naranjo, C., de los Santos, F., Álvarez-Fanjul, E. Meteorologically-driven circulation and flushing times of the Bay of Algeciras, Strait of Gibraltar, Marine Pollution Bulletin, submitted.

Sánchez-Garrido, J.C., Sannino, G., Liberti, L., García-Lafuente, J., Pratt, L., 2011. Numerical modeling of three-dimensional stratified tidal flow over Camarinal Sill, Strait of Gibraltar. J. Geophys. Res. 116, 1-17 http://dx.doi.org/10.1029/ 2011JC007093.

Sánchez-Román, A., García-Lafuente, J., Delgado, J., Sánchez-Garrido, J.C., Naranjo, C., 2012. Spatial and temporal variability of tidal flow in the Strait of Gibraltar. J. Mar. Syst. 98-99, 9-17 http://dx.doi.org/10.1016/j.jmarsys. 2012.02.011.

Sánchez-Román, A., Sannino, G., García-Lafuente, J., Carillo, A., Criado-Aldeanueva, F., 2009. Transport estimates at the western section of the Strait of Gibraltar: a combined experimental and numerical modeling study. J. Geophys. Res. 114, 34 http://dx.doi.org/10.1029/2008JC005023.

Sannino, G., Bargagli, A., Artale, V., 2002. Numerical modeling of the mean exchange through the Strait of Gibraltar. J. Geophys. Res. 107, 24 http://dx. doi.org/10.1029/2001JC000929.

Sannino, G., Bargagli, A., Artale, V., 2004. Numerical modeling of the semidiurnal tidal exchange through the Strait of Gibraltar. J. Geophys. Res. 109, 23 http://dx. doi.org/10.1029/2003JC002057.

Sannino, G., Sánchez-Garrido, J.C., Liberti, L., Pratt, L., 2013. Exchange flow through the Strait of Gibraltar as simulated by a $\sigma$-coordinate hydrostatic model and a z-coordinate non-hydrostatic model. In: Borzelli, E., Gačić, M., MalanotteRizzoli, P., Lionello, P. (Eds.), The Mediterranean Sea: Temporal Variability and Spatial Patterns. AGU Monograph Series. AGU, Washington, DC. 
Sanz, J.L., Acosta, J., Esteras, M., Herranz, P., Palomo, C., Sandoval, N., 1991. Prospección geofísica del Estrecho de Gibraltar (Resultados del programa Hércules 1980-1983). Publicaciones especiales del Instituto Español de Oceanografía, p. 48.

Thorpe, S.A., 2007. An Introduction to Ocean Turbulence. Cambridge University Press, Cambridge, United Kingdom.

Vlasenko, V., Stashchuk, N., Hutter, K., 2005. Baroclinic Tides: Theoretical Modelling and Observational Evidence. Cambridge University Press, Cambridge, United Kingdom.
Wang, D.P., 1989. Model of mean and tidal flows in the Strait of Gibraltar. Deep-Sea Res. Part A, Oceanogr. Res. Papers 36, 1535-1548 http://dx.doi.org/10.1016/ 0198-0149(89)90056-3.

Wang, D.P., 1993. The Strait of Gibraltar model: internal tide, diurnal inequality, and fortnightly modulation. Deep-Sea Res. 40, 1187-1203 http://dx.doi.org/10.1016 0967-0637(93)90133-N. 